\title{
Diversity, taxonomic composition, and functional aspects of fungal communities in living, senesced, and fallen leaves at five sites across North America
}

\author{
Jana M. U'Ren Corresp., 1,2 , A. Elizabeth Arnold ${ }^{1,3}$ \\ ${ }^{1}$ School of Plant Sciences, University of Arizona, Tucson, Arizona, United States of America \\ 3 Department of Ecology and Evolutionary Biology, University of Arizona, Tucson, Arizona, United States of America \\ Corresponding Author: Jana M. U'Ren \\ Email address: juren@email.arizona.edu
}

Background. Fungal endophytes inhabit symptomless, living tissues of all major plant lineages to form one of earth's most prevalent groups of symbionts. Many reproduce from senesced and/or decomposing leaves and can produce extracellular leaf-degrading enzymes, blurring the line between symbiotrophy and saprotrophy. To better understand the endophyte-saprotroph continuum we compared fungal communities and functional traits of focal strains isolated from living leaves to those isolated from leaves after senescence and decomposition, with a focus on foliage of woody plants in five biogeographic provinces ranging from tundra to subtropical scrub forest.

Methods. We cultured fungi from the interior of surface-sterilized leaves that were living at the time of sampling (i.e., endophytes), leaves that were dead and were retained in plant canopies (dead leaf fungi, DLF), and fallen leaves (leaf litter fungi, LLF) from 3-4 species of woody plants in each of five sites in North America. Our sampling encompassed 18 plant species representing two families of Pinophyta and five families of Angiospermae. Diversity and composition of fungal communities within and among leaf life stages, hosts, and sites were compared using ITS-partial LSU rDNA data. We evaluated substrate use and enzyme activity by a subset of fungi isolated only from living tissues vs. fungi isolated only from nonliving leaves.

Results. Across the diverse biomes and plant taxa surveyed here, culturable fungi from living leaves were isolated less frequently and were less diverse than those isolated from non-living leaves. Fungal communities in living leaves also differed detectably in composition from communities in dead leaves and leaf litter within focal sites and host taxa, regardless of differential weighting of rare and abundant fungi. All focal isolates grew on cellulose, lignin, and pectin as sole carbon sources, but none displayed ligninolytic or pectinolytic activity in vitro. Cellulolytic activity differed among fungal classes. Within Dothideomycetes, activity differed significantly between fungi from living vs. non-living leaves, but such differences were not observed in Sordariomycetes.

Discussion. Although some fungi with endophytic life stages clearly persist for periods of time in leaves after senescence and incorporation into leaf litter, our sampling across diverse biomes and host lineages detected consistent differences between fungal assemblages in living vs. non-living leaves, reflecting incursion by fungi from the leaf exterior after leaf death and as leaves begin to decompose. However, fungi found only in living leaves do not differ consistently in cellulolytic activity from those fungi detected thus far only in dead leaves. Future analyses should consider Basidiomycota in addition to the Ascomycota endophytes evaluated here, and should explore more dimensions of functional traits and 
persistence to further define the endophytism-to-saprotrophy continuum. 
1 Diversity, taxonomic composition, and functional aspects of fungal communities in

2 living, senesced, and fallen leaves at five sites across North America

3

4 Jana M. U'Ren ${ }^{1}$ and A. Elizabeth Arnold ${ }^{1,2}$

5

$6{ }^{1}$ School of Plant Sciences, University of Arizona, Tucson, Arizona, United States of America

72 Department of Ecology and Evolutionary Biology, University of Arizona, Tucson, Arizona,

8 United States of America

9

$10{ }^{*}$ Corresponding Author (current address):

11 Jana M. U'Ren'

12 Agricultural and Biosystems Engineering, University of Arizona, Tucson, Arizona, United States

13 of America

14 Email address: juren@email.arizona.edu 


\section{Abstract}

17 Background. Fungal endophytes inhabit symptomless, living tissues of all major plant lineages

18 to form one of earth's most prevalent groups of symbionts. Many reproduce from senesced

19 and/or decomposing leaves and can produce extracellular leaf-degrading enzymes, blurring the

20 line between symbiotrophy and saprotrophy. To better understand the endophyte-saprotroph

21 continuum we compared fungal communities and functional traits of focal strains isolated from

22 living leaves to those isolated from leaves after senescence and decomposition, with a focus on

23 foliage of woody plants in five biogeographic provinces ranging from tundra to subtropical scrub

24 forest.

Methods. We cultured fungi from the interior of surface-sterilized leaves that were living at the time of sampling (i.e., endophytes), leaves that were dead and were retained in plant canopies (dead leaf fungi, DLF), and fallen leaves (leaf litter fungi, LLF) from 3-4 species of woody plants in each of five sites in North America. Our sampling encompassed 18 plant species representing two families of Pinophyta and five families of Angiospermae. Diversity and composition of fungal communities within and among leaf life stages, hosts, and sites were compared using ITS-partial LSU rDNA data. We evaluated substrate use and enzyme activity by a subset of fungi isolated only from living tissues vs. fungi isolated only from non-living leaves.

Results. Across the diverse biomes and plant taxa surveyed here, culturable fungi from living leaves were isolated less frequently and were less diverse than those isolated from non-living leaves. Fungal communities in living leaves also differed detectably in composition from communities in dead leaves and leaf litter within focal sites and host taxa, regardless of differential weighting of rare and abundant fungi. All focal isolates grew on cellulose, lignin, and pectin as sole carbon sources, but none displayed ligninolytic or pectinolytic activity in vitro.

41 Cellulolytic activity differed among fungal classes. Within Dothideomycetes, activity differed 
42 significantly between fungi from living vs. non-living leaves, but such differences were not

43 observed in Sordariomycetes.

44

45 Discussion. Although some fungi with endophytic life stages clearly persist for periods of time

46 in leaves after senescence and incorporation into leaf litter, our sampling across diverse biomes

47 and host lineages detected consistent differences between fungal assemblages in living vs.

48 non-living leaves, reflecting incursion by fungi from the leaf exterior after leaf death and as

49 leaves begin to decompose. However, fungi found only in living leaves do not differ consistently

50 in cellulolytic activity from those fungi detected thus far only in dead leaves. Future analyses

51 should consider Basidiomycota in addition to the Ascomycota endophytes evaluated here, and

52 should explore more dimensions of functional traits and persistence to further define the

53 endophytism-to-saprotrophy continuum. 


\section{Introduction}

57 Fungal endophytes inhabit symptomless, living photosynthetic tissues of all major plant lineages

58 to form one of earth's most prevalent groups of symbionts (e.g. Arnold et al., 2010; U'Ren et al., 59 2012; Zimmerman \& Vitousek, 2012; Davey et al., 2013; Balínt et al., 2015). Known from a

60 wide range of biological provinces and agroecosystems, endophytes are a ubiquitous feature of

61 plant biology (e.g. Arnold \& Lutzoni, 2007; Saunders et al., 2010). Although classified together

62 due to ecological similarities (i.e., colonization and transmission patterns, in planta biodiversity,

63 and host interactions; see Rodriguez et al., 2009), endophytic fungi represent a diversity of

64 evolutionary histories, life history strategies, and functional traits that are only beginning to be

65 understood (reviewed by Porras-Alfaro \& Bayman, 2011).

66 Endophytes that inhabit photosynthetic tissues of most plants are horizontally

67 transmitted, form localized infections in aerial tissues, and represent highly diverse and often

68 novel lineages (e.g., Arnold et al., 2009; Gazis et al., 2012; Chen et al., 2015; U'Ren et al.,

69 2016) (Class 3 endophytes sensu Rodriguez et al., 2009; hereafter endophytes). Many

70 reproduce from senesced and/or decomposing leaves (Fröhlich \& Hyde, 1999; Promputtha et

71 al., 2007; Promputtha et al., 2010; U'Ren et al., 2010; Chaverri \& Gazis, 2011; He et al., 2012).

72 Some also produce extracellular leaf-degrading enzymes (Carroll \& Petrini, 1983; Korkama-

73 Rajala et al., 2008; Osono \& Hirose, 2011; Promputtha et al., 2010; Sun et al., 2011). Thus

74 many endophytes blur the line between symbiotrophy (during the endophytic phase) and

75 saprotrophy (when they occur in association with dead tissue), creating a challenge for

76 estimating trophic modes and the scale of fungal diversity based on species richness in

77 particular functional groups.

The prevalence of saprotrophic life phases among endophytes and the dynamics of such

fungi on the endophyte-to-saprotroph continuum are not yet clear. Current evidence suggests

80 that different groups of fungi may persist for longer or shorter periods in senesced leaves, but

81 the relevance of host lineages and abiotic factors is not yet understood in many cases. For 
82 example, Osono (2006) estimated that approximately two thirds of fungi with endophytic life

83 stages can persist in and degrade leaf litter. U'Ren et al. (2016) found that $74 \%$ of Xylariaceae

84 taxa were represented by isolates from asymptomatic plant tissues, senesced leaves, and

85 decomposing leaves, wood, bark, fruits, or flowers.

86 Some endophytes have ligninolytic and cellulolytic activity, cause mass loss from dead

87 plant tissues in vitro, and persist as litter decomposers over multiple years (e.g., some

88 Lophodermium spp. and xylariaceous fungi; see Koide et al., 2005; Osono, 2006; Korkama-

89 Rajala et al., 2008; Osono \& Hirose, 2009; Osono \& Hirose, 2011; see also Lindahl et al., 2007;

90 Yuan \& Chen, 2014). The presence of such fungi can increase respiration rates and

91 lignocellulolytic activity in litter, altering the litter substrate and the activity of subsequent

92 decomposers (see Koide et al., 2005; Šnajdr et al., 2011; He et al., 2013; Lin et al., 2015). In

93 contrast, other fungi with endophytic life phases may occupy litter only transiently, quickly

94 sporulating from senesced and decomposing leaves to infect living tissues (e.g., Rhabdocline

95 parkeri on Pseudotsuga menziesii and Coccomyes nipponicum on Camellia japonica; Stone,

96 1987; Koide et al., 2005). Their impact on litter degradation is less well known. Such patterns

97 can be documented via culture-based studies, but also by culture-free methods. For example,

98 fungal genotypes that were dominant in the phyllosphere of living leaves of Quercus petraea

99 disappeared by two to four months post abscission (Voříšková \& Baldrian, 2013). Similarly,

100 fungal communities in living leaves of European beech (Fagus sylvatica) in autumn differed from

101 fungi inhabiting leaf litter and bark in the following spring (Unterseher et al., 2013; but see

102 Peršoh et al., 2013).

103 Together, these studies speak to continuity between fungi that occur within living and

104 non-living leaves (see also Promputtha et al., 2007; Chaverri \& Gazis, 2011; Sun et al., 2011;

105 Peršoh et al., 2013; Voříšková \& Baldrian, 2013; Unterseher et al., 2013). However, it is not

106 clear whether such continuity is consistent in the distinctive plant and fungal communities

107 present in different biomes, nor whether patterns of persistence vary among phylogenetically 
108 diverse plants. It is also unclear whether endophytes in a given plant species might occur in

109 non-living leaves of co-occurring plant species: if undetected, such occurrences could alter our

110 understanding of the endophyte-saprotroph continuum. Finally, little is known about functional

111 traits of these fungi, raising the question: do strains that occur only living leaves differ in

112 substrate use and enzyme activity from those that consistently occur in both living and non-

113 living leaves?

114 The goal of this study was to explore the occurrence of endophytes in leaves after

115 senescence and incorporation into the leaf litter, with a focus on woody plants in five

116 biogeographic provinces ranging from tundra to subtropical scrub forest. Our surveys included

$117>7,000$ tissue pieces from living leaves, dead leaves in plant canopies, and recently fallen leaf

118 litter from 3-4 plant species in each site, yielding >2,000 fungal cultures. Here, we address (1)

119 the degree to which fungal communities within leaves differ as a function of leaf type (living,

120 senesced, or in leaf litter) at a given point in time; (2) whether such patterns are consistent

121 among diverse biogeographic/bioclimatic zones and host lineages; and (3) how functional

122 differences in carbon substrate utilization and enzyme activity reflect the occurrence of

123 particular fungi in living vs. non-living leaves.

124

\section{Materials and Methods}

126 We collected living leaves, senesced leaves in plant canopies, and leaf litter from five sites

127 representing distinct environmental, biological, and biogeographic regions of North America: the

128 Madrean Sky Island Archipelago of southeastern Arizona (AZC); the Appalachian Mountains of

129 western North Carolina ( $\mathrm{NCH}$ ); sub-tropical scrub forest in Florida (FLA); Beringian tundra and

130 boreal forest in the Seward Peninsula ecoregion of western Alaska (AKN); and inland, subalpine

131 tundra in the Interior Highlands of east-central Alaska (AKE) (see U'Ren et al., 2012 for site

132 details). Within each site, we selected three to four species of woody plants that were

133 representative of the community of the region (Table 1; Hultén, 1965; Radford et al., 1968; 
134 Barton, 1994; http://www.archbold-station.org/station/html/datapub/species/lists/plantlist.html).

135 Overall, we examined 18 host species representing two families of Pinophyta and five families 136 of Angiospermae (Table 1).

137 In each site we collected fresh tissues from one individual of each species in each of

138 three replicate microsites located ca. $30 \mathrm{~m}$ apart along a $100 \mathrm{~m}$ transect, for a total of 9-12 host

139 individuals per site. Within each microsite, focal plants occurred within close proximity to one

140 another (<1 m - $10 \mathrm{~m}$ apart), which allowed us to decouple spatial heterogeneity from host

141 associations (U'Ren et al., 2010). The only exception was Picea in AKN (see Table 1; U'Ren et

142 al., 2012).

143 From each individual we collected three small branches containing both healthy leaves

144 and dead leaves attached to branches, as well as leaves in below-crown leaf litter in an

145 intermediate state of decomposition (i.e., intact leaves with obvious changes in color and

146 texture). Leaves of deciduous plants were selected to represent the same year of growth.

148 Isolation of fungi-Plant material was transported in plastic bags to the laboratory and

149 processed within $24 \mathrm{~h}$ (except AKN; 48 h) following U'Ren et al. (2010). Each sample was

150 washed thoroughly in running tap water for $30 \mathrm{sec}$. Although putatively saprotrophic fungi can

151 be isolated from spores or hyphae on leaf surfaces (e.g., Promputtha et al., 2002; Promputtha et

152 al., 2007), all leaves were sterilized to exclude fungi that were incidental on leaf surfaces and to

153 maximize comparability with endophytic fungi (which are isolated from surface-sterilized leaves).

154 Leaves were cut into $2 \mathrm{~mm}^{2}$ segments and surface-sterilized by agitating sequentially in

$15595 \%$ ethanol for $10 \mathrm{sec}$, $10 \%$ bleach $(0.5 \% \mathrm{NaOCl})$ for $2 \mathrm{~min}$, and $70 \%$ ethanol for $2 \mathrm{~min}$

156 (Arnold et al., 2007). Segments were surface-dried under sterile conditions before being placed

157 on $2 \%$ malt extract agar (MEA) in Petri dishes (16 tissue segments/dish) or $1.5 \mathrm{ml}$

158 microcentrifuge tubes (1 segment/tube). Plates or tubes were sealed with Parafilm and

159 incubated under ambient light/dark condition at room temperature (ca. $21.5^{\circ} \mathrm{C}$ ) for up to one 
160 year. Emergent fungi were isolated into pure culture, vouchered in sterile water, and deposited

161 at the Robert L. Gilbertson Mycological Herbarium at the University of Arizona (ARIZ)

162 (Supplemental Table 1). Overall, 7,725 tissue segments were placed into culture (Table 2). All

163 samples relevant to this work were handled in accordance with standard operating procedures

164 for USDA permit P526P-1400151.

165

166 DNA extraction, PCR, and sequencing-Total genomic DNA was extracted directly from each

167 isolate following Arnold \& Lutzoni (2007). The nuclear ribosomal internal transcribed spacers

168 and 5.8s gene (ITS rDNA; ca. $600 \mathrm{bp}$ ) and an adjacent portion of the nuclear ribosomal large

169 subunit (LSU rDNA; ca. 500 bp) were amplified by PCR as a single fragment using primers

170 ITS1F or ITS5 and LR3 (White et al., 1990; Gardes \& Bruns, 1993; Vilgalys \& Hester, 1990; ITS

171 rDNA-partial LSU rDNA) following U'Ren et al., (2010). ITS rDNA was amplified using primers

172 ITS1 and ITS4 (White et al., 1990) for 19 isolates that failed to amplify using the primers listed

173 above. PCR conditions are described in U'Ren et al. (2010).

174 PCR products were evaluated by staining with SYBR Green I (Molecular Probes,

175 Invitrogen; Carlsbad, CA) after electrophoresis on a $1 \%$ agarose gel. All positive amplicons

176 yielded single bands. PCR products were cleaned, quantified, normalized, and sequenced

177 directly with the Applied Biosystems BigDye® Terminator v3.1 cycle sequencing kit and the

178 original PCR primers at the University of Arizona Genetics Core. Bidirectional sequencing was

179 performed on an Applied Biosystems 3730xI DNA Analyzer (Foster City, CA).

$180 \quad$ The software applications phred and phrap (Ewing \& Green, 1998; Ewing et al., 1998)

181 were used to call bases and assemble contigs with automation provided by the ChromaSeq

182 package in Mesquite v. 1.06 (http://mesquiteproject.org). Base calls were verified by inspection

183 of chromatograms in Sequencher v. 4.5 (Gene Codes, Ann Arbor, MI). Overall, 1,037 new

184 sequences were analyzed in conjunction with 1,030 sequences previously published as part of a

185 study of endophytic and endolichenic fungal communities (U'Ren et al., 2009; U'Ren et al., 
186 2012; U'Ren et al., 2016). Each sequence was queried against the non-redundant

187 UNITE+INSDC database (v. 7.97.31.01, released 2016-01-31) using the Ribosomal Database

188 Project (RDP) naïve Bayesian classifier (Wang et al., 2007) with a confidence threshold cutoff of

$18980 \%$ to estimate taxonomic placement. Basidiomycota comprised $<6 \%$ of the overall data set

190 and were excluded from all analyses due to their rarity, potentially reflecting use of a culture

191 medium demonstrated to recover a high diversity of ascomycetous endophytes (Fröhlich \&

192 Hyde, 1999; Arnold, 2002). All sequences have been deposited in GenBank (Supplemental

193 Table 2).

194

195 Species richness and diversity-Operational taxonomic units (OTU) were defined using ITS-

196 partial LSU rDNA sequences. To designate OTU a distance matrix based on pairwise

197 Needleman-Wunsch alignments was generated with the needledist module in ESPRIT (Sun et

198 al., 2009) under the default parameters. Gaps of any length were treated as a single

199 evolutionary event and terminal gaps were not penalized (Sun et al., 2009). We used mothur

200 (Schloss et al., 2009) to cluster sequences into OTU using the complete-linkage method (i.e.,

201 furthest neighbor) and to calculate richness and OTU overlap among communities. Sequences

202 were assembled into OTU based on sequence similarities ranging from $95 \%$ to $100 \%$ following

203 U'Ren et al. (2012). Results are presented at the genotype level (i.e., 100\% sequence similarity)

204 and at the putative species level (i.e., 95\% sequence similarity; see U'Ren et al., 2009).

205 Previous assessment of four endophyte-rich genera in the Sordariomycetes and

206 Dothideomycetes demonstrated that ca. 5\% ITS rDNA divergence (i.e., 95\% sequence

207 similarity) conservatively estimates sister species boundaries when compared against published

208 phylogenies (U'Ren et al., 2009; see also Liggenstoffer et al. 2010). OTU richness increased

209 when more stringent sequence similarity levels were used (e.g., 348 OTU were estimated at

$21097 \%$ sequence similarity vs. 306 OTU at 95\% sequence similarity), generally reflecting an

211 increase in singletons that could not be used for comparative analyses. Even so, estimates of 
212 overlap among different leaf types were congruent based on $95-100 \%$ sequence similarity

213 groups.

214 OTU accumulation curves (Fig. 1; Supplemental Fig. 1), rarefaction analyses, estimates

215 of total richness (bootstrap and abundance coverage estimator (ACE), recommended by Hortal

216 et al., 2006), and diversity were inferred in EstimateS v. 8.0

217 (http://viceroy.eeb.uconn.edu/EstimateS) using 50 randomizations of sample order without

218 replacement. Fisher's alpha, a parameter of the log series model that is theoretically

219 independent of sample size (Fisher et al., 1943; Taylor, 1978; Magurran, 2004), was chosen to

220 measure fungal diversity. Fisher's alpha is robust for comparing diversity among communities

221 that are sampled unequally (given variation in isolation frequency) and are characterized by a

222 log-series distribution of OTU abundance (Magurran, 2004).

223 We analyzed isolation frequency and diversity as a function of site, host family, and leaf

224 type (i.e., living, senesced, or leaf litter) using multiple regression with these explanatory factors

225 as main effects. Isolation frequency and diversity were logit- and log transformed, respectively,

226 to achieve normality. The fit of each model was assessed using a lack-of-fit $F$ test. Pairwise

227 comparisons between fungal communities from different leaf types were computed using least-

228 squares means contrasts. Analyses were done in JMP v. 9.0.0 (SAS Institute, Cary, NC).

229

230 Similarity of fungal assemblages - We used several approaches to examine the relationship

231 of site, host, and leaf type to the composition of fungal communities. First, we used analysis of

232 similarity (ANOSIM) coupled with visualization by non-metric multidimensional scaling (NMDS)

233 to assess whether fungal communities differed significantly among sites (Supplemental Fig. 2).

234 Because fungal communities did differ among sites, NMDS ordinations also were computed

235 within each site to examine the effect of host species and leaf type (Supplemental Fig. 2).

236 ANOSIM and NMDS were conducted in PAST v. 1.88 (Hammer et al., 2001) following U'Ren et 237 al. (2012). 
Second, these analyses were complemented by hierarchical clustering to clarify the relationships among fungal communities in different sites and leaf types. The dendrogram was generated using the unweighted pair-group average (UPGMA) algorithm. Hierarchical clustering was conducted in PAST v. 1.88 (Hammer et al., 2001) using 10,000 bootstrap replicates. examine variation in community composition as a function of (1) leaf type and host species, while constraining permutations with each site; and (2) leaf type, while constraining permutations with each site and each host species. PERMANOVA was implemented with the adonis and permute functions in the $\mathrm{R}$ (R Core Team) package vegan (Oksanen et al., 2015). ANOSIM, NMDS, hierarchical clustering, and PERMANOVA were conducted using all nonsingleton OTU (i.e., those occurring more than once in the entire dataset) to minimize the potential under-estimation of similarity due to under-sampling (Manter \& Bakker, 2015). The Morisita-Horn metric of similarity was used to minimize sensitivity to under-sampling, as it reflects the distribution of abundant taxa (Beck et al., 2013). Host individuals/leaf types from which $<4$ isolates were sequenced were excluded from all analyses (see Table 1). combination, and because distributions of rare taxa can be informative, we examined community structure for all OTU grouped by site and leaf type using OTUshuff (Manter \& Bakker, 2015). To estimate the influence of rare and abundant taxa on community similarity, OTUshuff uses a variably weighted version of the Odum index (wOdum). At $\alpha=1, D_{\text {wOdum }}$ is equal to $D_{\text {Odum; }}$ when $\alpha<1$, the influence of abundant taxa will be down-weighted; and when $\alpha>$ 1 , the influence of abundant abundance taxa will be up-weighted. We varied the alpha weighting

260 factor from 0 to 4 to test the null hypothesis that samples from different leaf types within a site 261 represent the same community (Supplemental Table 1). Analyses were conducted using a

262 Monte Carlo simulation with 1000 iterations. Low isolation frequency of endophytes prevented 263 comparisons of endophytes and DLF/LLF in one site (AKE). 
265 Functional characterization of fungal isolates-We compared in vitro growth and cellulolytic,

266 pectinolytic, and ligninolytic activity for representative isolates of eight OTU found only in living

267 leaves and nine OTU found only in non-living leaves. Each OTU was represented by a single

268 isolate. Leaf type designation for each OTU (i.e., living leaves vs. non-living leaves) was based

269 on host and substrate information from a larger collection of endophytic and endolichenic fungi

270 (see U'Ren et al., 2012), as well as BLASTn comparisons to the NCBI nr database. When

271 possible, OTU representing each leaf status (living, non-living) were chosen from the same

272 class (i.e., Sordariomycetes and Dothideomycetes). However, paired comparisons were not

273 possible for Pezizomycetes or Leotiomycetes because no OTU in those classes were found

274 only as endophytes.

275 Pure cultures were started on $2 \%$ MEA plates and were allowed to grow for up to $7 \mathrm{~d}$. At

276 that point $5 \mathrm{~mm}$ agar plugs containing actively growing mycelium were placed on water agar

277 plates (WA; pH 5.6, 1.5\% agar, containing $50 \mathrm{ml}$ 20X nitrate salts, $1 \mathrm{ml}$ 1000X trace elements,

278 and $1 \mathrm{ml}$ vitamin solution per liter; see Tucker \& Orbach, 2007) amended with (1) $5 \mathrm{~g}$

279 carboxymethylcellulose (cellulose substitute; Sigma-Aldrich, St. Louis, Missouri, USA); (2) $10 \mathrm{~g}$

280 citrus pectin (grade 1 from citrus fruits, Sigma-Aldrich); or (3) $0.5 \mathrm{~g}$ indulin (lignin substitute;

281 Mead-Westvaco, Richmond, Virginia, USA) as the sole carbon source. Three replicates were

282 prepared for each isolate per medium. A culture with verified enzymatic activity was used as

283 the positive control.

284 Cultures were grown for 5-28 days in a temperature controlled room at $26^{\circ} \mathrm{C}$ under

285 constant light conditions. Once cultures were ca. 3-4 cm in diameter, plates were stained with

286 aqueous solutions of $0.2 \%$ (wt/vol) Congo red, equal parts of $1.0 \%$ (wt/vol) $\mathrm{FeCl}_{3}$ and

$287 \mathrm{~K}_{3}[\mathrm{Fe}(\mathrm{CN})]_{6}$, or $0.05 \%$ (wt/vol) ruthenium red to detect cellulolytic, pectinolytic, and ligninolytic

288 activity, respectively (modified from Gazis et al., 2012; Cotty et al., 1990). Following staining,

289 plates were rinsed with either $1 \mathrm{M}$ sodium chloride (for cellulose plates) or deionized water 
290 (pectin and lignin plates) and the colony diameter and clearing at the periphery of mycelial

291 growth (i.e., extra-hyphal clearing) of each isolate was measured.

292 Average growth rates (colony diameter/days of growth) were compared on each carbon

293 source as a function of fungal taxonomy at the class level and leaf type using non-parametric

294 tests. The proportion of isolates that demonstrated diagnostic clearing was compared as a

295 function of leaf type using two-tailed Fisher's exact tests. Where present, the amount of clearing

296 at the periphery of mycelial growth was scaled by growth rate and compared using Wilcoxon

297 rank sum tests.

298 Mantel tests were used to examine the relationship of fungal genetic distance to patterns

299 of cellulolytic activity and growth rates on different carbon sources. ITS-partial LSU rDNA

300 sequences for Sordariomycetes and Dothideomycetes isolates were aligned using MAFFT

301 v6.821b (Katoh \& Toh, 2008) with the L-INS-I setting for high accuracy. Ambiguously aligned

302 nucleotides were masked using the Gblocks server v.0.91b (Castresana, 2000) with parameters

303 to allow for less stringent selection (i.e., to allow for smaller final blocks; to allow gap positions

304 within the final blocks; and to allow less strict flanking positions) resulting in retention of $83 \%$ of

305 the original 1,223 positions. A distance matrix was calculated in PAUP* v4.0 (Swofford, 2003)

306 using uncorrected distances (p). Pairwise distance matrices for (1) cellulolytic activity; (2)

307 average growth rate on cellulose; (3) average growth rate on pectin; and (4) average growth

308 rate on lignin were calculated in JMP v. 9.0.0. Mantel tests were performed in R with the ade4

309 package (Dray \& Dufour, 2007) using 9,999 permutations.

310

\section{Results}

312 We obtained 2,618 fungal isolates from the interior of 7,725 leaf segments representing living

313 leaves (i.e., endophytes), dead leaves in plant canopies (dead leaf fungi, DLF), and leaf litter

314 (leaf litter fungi, LLF; Table 1) of 18 host species. ITS rDNA-partial LSU rDNA data obtained 
315 from 2,064 isolates of Ascomycota comprised 555 unique genotypes (100\% sequence

316 similarity) and 306 putative species (i.e., OTU at 95\% sequence similarity) (Table 1).

317 Our sampling effort did not capture the estimated richness of cultivable leaf-associated

318 fungi for the entire study (Fig. 1; Table 2). However, sampling in 8 of 15 site-leaf type

319 combinations encompassed the local richness of fungi based on bootstrap estimates (Table 2),

320 and average differences between bootstrap and ACE estimates and the upper 95\% confidence

321 intervals around observed richness were only 3.0 and 13.7 OTU, respectively (Table 2; see also

322 Supplemental Fig. 1). Therefore, we used these data to compare communities of culturable

323 fungi as described below.

324

325 Isolation frequency and diversity-Isolation frequency and diversity differed as a function of 326 site, host family, and leaf type (Table 3). Across all sites, fungi were isolated less frequently

327 from living leaves than from dead leaves in plant canopies or leaf litter (Table 3). Endophytes

328 were isolated from $24 \% \pm 26 \%$ (mean \pm SD) of leaf segments per host species (range: $0-96 \%$;

329 Table 2). DLF and LLF were isolated from $36 \% \pm 23 \%$ (range, $0-71 \%$ ) and $41 \% \pm 26 \%$ (range,

$3301-85 \%$ ) of leaf segments per host species, respectively (Table 1). A greater number of hosts

331 failed to yield cultures from living leaves (i.e., Salix pulchra and Betula nana at AKN and

332 Quercus rugosa at AZC; Table 2) compared to a single host for non-living leaves (Betula nana 333 at AKN: only LLF were obtained; Table 1).

334 Endophytes also were less diverse than DLF and LLF (Table 3). Cumulative diversity of

335 fungi from non-living leaves over the entire study was 1.7 to 1.8 times that of fungi from living 336 leaves (Table 2).

338 Fungal community analyses-Fungal communities differed among sites (Fig. 2; Supplemental

339 Fig. 2A). Within sites, communities differed among host species and leaf type (Fig. 2; Table 4;

340 Supplemental Fig. 2B-2D). 
342 from the same community at all levels of alpha $(P<0.05$; Supplemental Table 1$)$. Preferentially

343 weighting rare species decreased similarity between endophytes and DLF, and between DLF

344 and LLF, relative to analyses in which abundant species were weighted preferentially. In

345 contrast, variably weighting rare or abundant OTU had no discernible effect on similarity

346 estimates of endophytes and LLF, which were consistently low (Fig. 3; Supplemental Table 1).

347 Overall, $29 \%$ of non-singleton OTU (Supplemental Fig. 3) and 52\% of common OTU

348 (those represented by $>5$ sequenced isolates) were found in both living and non-living leaves

349 (Fig. 4). After removing infrequent taxa, OTU from only one leaf status were rare: only 3\%, 5\%,

350 or $8 \%$ of OTU were unique to living leaves, dead leaves in plant canopies, or leaf litter,

351 respectively (Fig. 4; see also Supplemental Fig. 4). However, OTU that were highly abundant in

352 leaf litter were seldom found as endophytes (Fig. 4), and the abundance of OTU from leaf litter

353 was not correlated with abundance of the same OTU in living leaves (Supplemental Table 3).

355 Substrate utilization-We compared in vitro growth for representative isolates of eight OTU

356 found only in living leaves and nine OTU found only in non-living leaves. All isolates, regardless

357 of leaf type of origin, grew on cellulose, lignin, and pectin as sole carbon sources.

358 We focused on OTU in two classes to evaluate the relationship of substrate utilization to 359 leaf type of origin. Dothideomycetes from living leaves grew more rapidly than those isolated 360 originally from non-living leaves on all three carbon sources (Fig. 5C). However, growth of

361 Sordariomycetes on cellulose, lignin, or pectin did not differ for fungi from living vs. non-living 362 tissues (Fig. 5C).

363 We found no significant correlation between genetic distance and differences in growth

364 on cellulose or lignin, but differences in fungal growth on pectin were correlated with genetic

365 distance between isolates (Supplemental Table 3). 
367 Enzyme activity-Extra-hyphal clearing (indicative of enzyme activity) was observed for

368 isolates only on media containing cellulose as the sole carbon source. Only the positive control

369 displayed in vitro ligninolytic or pectinolytic activity.

370 The number of OTU with detectable cellulolytic activity vs. no cellulolytic activity did not

371 differ as a function of leaf type of origin (Supplemental Table 3). For OTU with detectable

372 clearing, the degree of cellulolytic activity differed significantly among fungi from different

373 classes, with Leotiomycetes from non-living leaves displaying the greatest enzymatic activity

374 (Table 5; Fig. 5A). Dothideomycetes from non-living leaves had greater cellulolytic activity

375 compared to those isolated only from living leaves (Fig. 5B). Sordariomycetes from different leaf

376 types did not differ significantly in cellulolytic activity (Fig. 5B). We found no significant

377 correlation between genetic distance and differences in cellulolytic activity (Supplemental Table

378 3).

379

380

Discussion

381 The occurrence of some endophytic fungi in dead leaves and/or leaf litter and the ability of some endophytes to produce extracellular leaf-degrading enzymes in a manner consistent with saprotrophs (Carroll \& Petrini, 1983; Fröhlich \& Hyde, 1999; Promputtha et al., 2007; KorkamaRajala et al., 2008; Promputtha et al., 2010; U'Ren et al., 2010; Chaverri \& Gazis, 2011; Osono \& Hirose, 2011; Sun et al., 2011; He et al., 2012) has led to suggestions that many endophytes are incidental symbionts that exist in leaves as a prelude to completing their life cycles as primary decomposers. Here, we explore the endophyte-saprotroph continuum, with the goal of understanding the degree to which endophytes may occur in non-living tissues in diverse plants and terrestrial biomes and whether ecological patterns reflect fungal carbon substrate utilization patterns and enzyme activity. 
392 Fungal communities differ in living and non-living leaves-As a whole, culturable fungi

393 inhabiting living leaves were isolated less frequently and were less diverse than those in non-

394 living leaves. This may reflect the plant actively restricting fungal colonization within leaves,

395 limited growth by fungi within living leaves for intrinsic reasons, or culturing biases (see below).

396 Culturable fungal communities in living leaves also differed in composition from communities in

397 senesced leaves and leaf litter, regardless of differential weighting of rare and abundant taxa.

398 These observations are congruent with colonization of senesced and abscised leaves by

399 additional epiphytic- and/or litter fungi (see Lindahl et al., 2007). As leaves senesce, epiphytic

400 fungi can colonize the interior of leaves rapidly, leading to a subsequent decline in the relative

401 abundance of endophytic taxa (Cabral, 1985; Stone, 1987; Osono, 2002; but see Peršoh et al.,

402 2013). When we examine common OTU as a function of their abundance in leaves of each

403 type, 35\% have patterns of leaf-association that match that of ambient, non-endophytic fungi

404 colonizing leaf interiors after leaf death (Fig. 4). Additional fungi appear to colonize fallen leaves

405 from the underlying litter layer or from other sources; these represented a relatively small

406 number ( $8 \%$ of OTU), potentially reflecting preferential growth of Ascomycota (vs.

407 Basidiomycota and other fungal taxa) on the culture medium used here.

$408 \quad$ Although culturable ascomycete communities as a whole differed significantly as a

409 function of leaf type, $29 \%$ of non-singleton OTU (Supplemental Fig. 3) and $52 \%$ of common

410 OTU (OTU represented by $>5$ sequences) from living leaves also inhabited non-living leaves.

411 These OTU typically were present in living vs. non-living leaves at different abundances (Fig. 4).

412 This is consistent with previous studies that noted the transitory nature of many endophytes in

413 leaf litter (Stone, 1987; Hudson, 1968; Osono \& Takeda, 2001), as well as the quick turnover in

414 litter of all phyllosphere fungi (including both epiphytes and endophytes). For example,

415 Voříšková \& Baldrian (2013) found that the majority of phyllosphere OTU were absent from

416 leaves two to four months after abscission. In contrast, a greater proportion of Xylariaceae

417 appear to inhabit living leaves, as well as decomposing leaves, wood, and fruit (U'Ren et al., 
418 2016). Factors that mediate these shifts merit further exploration, including the exhaustion of

419 readily available sugars, the ability of some fungi to decompose structural polymers, and

420 processes relevant to competitive exclusion or antibiosis (see Osono, 2006; Yuan et al., 2011;

421 Yuan \& Chen, 2014).

422

423

Differences in fungal communities as a function of leaf type are consistent among sites

and host lineages-Although the same major lineages of Ascomycota were present in all sites,

425 fungal communities differed among sites in terms of the relative abundance of those lineages,

426 as well as at finer taxonomic levels. In some cases, these differences may reflect unequal

427 recovery of fungi from different plant lineages: in $A K N$ and $A Z C$, for example, fungi were more

428 commonly isolated from coniferous hosts, and isolation frequency from angiosperms was low

429 compared to other sites. Yet, communities still differed between sites when lineages were

430 sampled equally (e.g., NCH and FLA), consistent with our previous results on endophytic and

431 endolichenic fungi from the same locations (U'Ren et al., 2012) and with other studies

432 illustrating the influence of climate and biogeographic factors on endophyte community

433 composition (e.g., Davis \& Shaw, 2008; Zimmerman \& Vitousek 2012; Langenfeld et al., 2013).

434 Within each site we found that fungal community composition differed markedly among

435 host species. These results are consistent with the view that plant defenses may mediate

436 infection and colonization by particular endophytes (see Schulz \& Boyle, 2005), with persistent

437 signatures of host chemistry or other traits contributing to the structure of fungal assemblages in

438 non-living leaves. Previous work has shown that litter traits (i.e., nutrient quality or other traits

439 relevant to host species) may have stronger effects on fungal community composition than other

440 environmental factors (Aneja et al., 2006; Šnajdr et al., 2011; Bray et al., 2012; Urbanová et al.,

441 2015). More generally, the consistent differences observed between fungal communities in

442 living vs. non-living leaves in different hosts and sites suggest that factors influencing the

443 ecology and evolution of plant-fungal associations may be relatively consistent at large scales. 
445 Evaluating the strength of our conclusions-Differences in fungal communities observed

446 here could result from artifacts of insufficient sampling, unintentional comparisons among leaves

447 of different ages (e.g., leaf litter representing previous years of growth vs. living leaves

448 representing the current year), and/or biasing our work toward fungi that are readily cultured on

449 standard nutrient media or specific isolation techniques (see Unterseher \& Schnittler, 2009 for

450 comparison of fragment plating vs. dilution-to-extinction culturing). The last issue might be

451 especially problematic for fungi that do not normally occur in symbiosis and/or have the capacity

452 to grow on non-living substrates vs. those with a symbiotrophic lifestyle. However, several lines

453 of evidence suggest our conclusions are robust. First, species accumulation curves and

454 bootstrap estimates of species richness for all sites and site/leaf-type combinations indicate our

455 sampling was at or near statistical completion for culturable fungi. Second, although leaves may

456 have emerged at different times and thus been subject to different pools of inoculum (see

457 Arnold \& Herre, 2003), patterns are consistent across hosts from different microsites,

458 geographic locations, and host species, including both deciduous and evergreen angiosperms

459 as well as conifers. Third, although missing species found using culture-independent methods

460 have the potential to alter our estimates of diversity and the degree of overlap among leaf-types

461 (Arnold et al., 2007; Gallery et al., 2007; Jumpponen \& Jones, 2009; U'Ren et al., 2014, Bálint

462 et al., 2015), the consistent patterns we observed across hosts and sites suggest that our

463 conclusions are valid for prevalent members of these fungal communities. In addition, our

464 results are congruent with similar studies that used culture-free methods (Voříšková \& Baldrian,

465 2013).

466 The abundance and identity of endophytes in leaf litter typically differs as a function of

467 leaf age and season (Hirose \& Osono, 2006; Osono, 2006; Peršoh et al., 2013). Had we

468 sampled freshly fallen leaves, communities may have been more similar among leaf-types;

469 conversely, greater differences may have been observed had we examined more thoroughly 
470 decomposed leaves (see Voříšková \& Baldrian, 2013). Accordingly, our estimates of overlap

471 among endophytic and saprotrophic communities are restricted to culturable members from leaf

472 litter in a moderate state of decay sampled during the summer. However, the relatively

473 consistent patterns observed from tundra to subtropical communities suggest strong signal in

474 the data.

475 Importantly, the relative abundance of isolates in living or dead tissues is not necessarily

476 indicative of an isolate's ability to decompose plant tissues. This prompted our evaluation of

477 substrate use and enzyme activity (below). Future studies that assess endophyte and litter

478 communities over multiple time points (including multiple time points for living leaves and during

479 the first weeks of decomposition) in combination with functional assays and metatranscriptomic

480 methods, will provide much-needed insight into the persistence and functional roles of

481 endophytes as decomposers.

482

483 Functional differences-The limited persistence of endophytes in leaf litter over time led us to conduct a preliminary investigation of in vitro patterns of substrate use between OTU found only

in living tissues vs. only in non-living tissues in our surveys (including the larger sampling from

U'Ren et al., 2012). Across four classes of Pezizomycotina, cellulolytic activity differed primarily

as a function of class-level taxonomy. However, cellulolytic activity was not correlated with finerscale genetic relationships within Sordariomycetes and Dothideomycetes. Although some isolates demonstrated high levels of cellulolytic activity (e.g., Leotiomycetes representing the Rhytismataceae and Helotiaceae), our study differs from previous ones in that none of our

491 isolates had detectable ligninolytic or pectinolytic activity (see Oono et al., 2014; Fouda et al., 492 2015). We detected differences in growth rate on pectin-, lignin-, and cellulose media in the

493 Dothideomycetes, and in this class cellulolytic activity differed between fungi from living vs. non-

494 living leaves. However, such differences were not observed in the Sordariomycetes. Overall,

495 more precise measurements investigating a broader array of enzymes (e.g., $\beta$-mannanase, 
496 xylanase, laccase, etc.), in conjunction with genomic and transcriptomic studies of multiple

497 isolates per OTU, are necessary to identify functional differences among fungi associated with

498 leaves at different life stages.

499

500 Conclusions-Approximately half of the common OTU found here occurred in both living and

501 non-living leaves. However, our sampling across diverse biomes and host lineages detected

502 consistent differences in living vs. non-living leaves in terms of diversity and fungal community

503 composition. Fungi that were common in decomposing leaves collected from leaf litter were not

504 typically common in living leaves of the same plants. Thus some fungi with endophytic life

505 stages clearly persist for periods of time in leaves after senescence and incorporation into leaf

506 litter, with shifts after leaf death and in the early stages of decomposition likely reflecting

507 incursion by additional fungi from the leaf exterior. Overall, our data — while preliminary in some

508 regards - suggest that focal isolates found in dead and fallen leaves did not differ consistently

509 from those in living leaves in terms of their capacity to use pectin, lignin, and cellulose as their

510 sole carbon sources, nor in the degree of cellulolytic activity displayed in vitro. We suggest that

511 culturable fungi with endophytic life stages may not persist in decomposing leaves once

512 cellulose and hemicellulose are depleted. Future analyses should optimize methods to culture

513 both Basidiomycota and Ascomycota endophytes, and should explore more dimensions of

514 functional traits and persistence to further define the endophytism-to-saprotrophy continuum.

515

516 Acknowledgements

517 We thank E. Gaya, K. Molnár, T. Abbey, K. Arendt, F. Santos, M. Gunatilaka, M. Hoffman, M.

518 del Olmo R., M. Orbach, D. L. Taylor, and especially F. Lutzoni and J. Miadlikowska for field and

519 laboratory assistance, D. R. Maddison for sharing pre-release versions of Mesquite and

520 ChromaSeq, P. Degnan, T. Wheeler, J. Stajich, S. Huse, S.J. Miller, Y. Sun, and N. Zimmerman

521 for computational assistance, and R. J. Steidl and R. Kaczorowski for assistance with statistical 
522 analyses. We gratefully acknowledge the NSF Fungal Environmental Sampling and Informatics

523 Network (FESIN; DEB-0639048 to T. Bruns, K. Hughes, and AEA) for fostering discussion that

524 informed this work, and N. Zimmerman and five anonymous reviewers for helpful comments on

525 the manuscript.

526

\section{References}

528 Aneja, M. K., S. Sharma, F. Fleischmann, S. Stich, W. Heller, G. Bahnweg, J. C. Munch, and M.

529 Schloter. 2006. Microbial colonization of beech and spruce litter - influence of decomposition

530 site and plant litter species on the diversity of microbial community. Microbial Ecology 52:

$531127 \mathrm{e} 135$.

532

533

534

535

536

537

538

539

540

541

542

543

544

545

546

547

548

549

550

551

552

553

554

555

556

557

558

559

560

561

562

563

Arnold AE. 2002. Fungal endophytes in Neotropical trees: abundance, diversity and ecological interactions [doctoral dissertation]. Tucson: Univ. Arizona Press. 337 p.

Arnold, A. E., D. A. Henk, R. L. Eells, F. Lutzoni and R. Vilgalys. 2007. Diversity and

phylogenetic affinities of foliar fungal endophytes in loblolly pine inferred by culturing and environmental PCR. Mycologia 99: 185-206.

Arnold, A. E. and E. A. Herre. 2003. Canopy cover and leaf age affect colonization by tropical fungal endophytes: ecological pattern and process in Theobroma cacao (Malvaceae). Mycologia 95: 388-398.

Arnold, A. E., L. J. Lamit, M. Bidartondo, C. Gehring and H. S. Callahan. 2010. Interwoven branches of the plant and fungal trees of life. New Phytologist 185: 874-878.

Arnold, A. E. and F. Lutzoni. 2007. Diversity and host range of foliar fungal endophytes: are tropical leaves biodiversity hotspots? Ecology 88: 541-549.

Arnold, A. E., J. Miadlikowska, K. L. Higgins, S. D. Sarvate, P. Gugger, A. Way, V. Hofstetter, F. Kauff and F. Lutzoni. 2009. A phylogenetic estimation of trophic transition networks for ascomycetous fungi: are lichens cradles of symbiotrophic fungal diversification? Systematic Biology 58: 283-297.

Balínt, M., L. Bartha, R. B. O’Hara, M. S. Olson, J. Otte, M. Pfenninger, A. L. Robertson, P. Tiffin and I. Schmitt. 2015. Relocation, high-latitude warming and host genetic identity shape the foliar fungal microbiome of poplars. Molecular Ecology 24: 235-248.

Barton, A. M. 1994. Gradient analysis of relationships among fire, environment, and vegetation in a southwestern USA mountain range. Bulletin of the Torrey Botanical Club 121: 251-265.

Beck, J., J. D. Holloway and W. Schwanghart. 2013. Undersampling and the measurement of beta diversity. Methods in Ecology and Evolution 4: 370-382 
565 Bray, S. R., K. Kitajima, M. C. Mack. 2012. Temporal dynamics of microbial com- munities on

566

567

568

569

570

571

572

573

574

575

576

577

578

579

580

581

582

583

584

585

586

587

588

589

590

591

592

593

594

595

596

597

598

599

600

601

602

603

604

605

606

607

608

609

610

611 decomposing leaf litter of 10 plant species in relation to decomposition rate. Soil Biology \& Biochemistry 49: 30e37.

Cabral, D. 1985. Phyllosphere of Eucalyptus viminalis: dynamics of fungal populations. Transactions of the British Mycological Society 85: 501-511.

Carroll, G. C. and O. Petrini. 1983. Patterns of substrate utilization by some fungal endophytes from coniferous foliage. Mycologia 75: 53-63.

Castresana, J. 2000. Selection of conserved blocks from multiple alignments for their use in phylogenetic analysis. Molecular Biology and Evolution 17: 540-552.

Chaverri, P. and R. O. Gazis. 2011. Linking ex planta fungi with their endophytic stages: Perisporiopsis, a common leaf litter and soil fungus, is a frequent endophyte of Hevea spp. and other plants. Fungal Ecology 4: 94-102.

Chen, K-H., J. Miadlikowska, K. Molnár, A. E. Arnold, J. M. U'Ren, E. Gaya, C. Gueidan and F. Lutzoni. 2015. Phylogenetic analyses of eurotiomycetous endophytes reveal their close affinities to Chaetothyriales, Eurotiales, and a new order - Phaeomoniellales. Molecular Phylogenetics and Evolution 85: 117-130.

Davis, E. C. and A. J. Shaw. 2008. Biogeographic and phylogenetic patterns in diversity of liverwort-associated endophytes. American Journal of Botany 95: 914

Dray, S. and A. B. Dufour. 2007. The ade4 package: implementing the duality diagram for ecologists. Journal of Statistical Software 22: 1-20.

Fisher, R. A., A. S. Corbet and C. B. Williams. 1943. The relation between the number of species and the number of individuals in a random sample of an animal population. Journal of Animal Ecology 12: 42-58.

Fouda, A. H., S. El-Din Hassan, A. M. Eid and E. El-Din Ewais. 2015. Biotechnological applications of fungal endophytes associated with medicinal plant Asclepias sinaica (Bioss.). Annuals of Agricultural Sciences 60: 95-104.

Fröhlich, J. and K. D. Hyde. 1999. Biodiversity of palm fungi in the tropics: are global fungal diversity estimates realistic? Biodiversity and Conservation 8: 977-1004.

Gallery, R., J. W. Dalling and A. E. Arnold. 2007. Diversity, host affinity, and distribution of seedinfecting fungi: A case study with neotropical Cecropia. Ecology 88: 582-588.

Gardes, M. and T. D. Bruns. 1993. ITS primers with enhanced specificity of basidiomycetes: application to the identification of mycorrhizae and rusts. Molecular Ecology 2: 113-118.

Gazis, R., J. Miadlikowska, F. Lutzoni, A. E. Arnold and P. Chaverri. 2012. Culture-based study of endophytes associated with rubber trees in Peru reveals a new class of Pezizomycotina:

612 Xylonomycetes. Molecular Phylogenetics and Evolution 65: 294-304.

613 
614 Gazis, R., A. Kuo, R. Riley, K. LaButti, A. Lipzen, J. Lin, M. Amirebrahimi, C. N. Hesse, J. W.

615 Spatafora, B. Henrissat, M. Hainaut, I. Grigoriev and D. S. Hibbett. 2016. The genome of Xylona

616 heveae provides a window into fungal endophytism. Fungal Biology 120: 26-42.

617

618

619

620

621

622

623

624

625

626

627

628

629

630

631

632

Hammer, Ø., D. A. T. Harper and P. D. Ryan. 2001. PAST: Paleontological statistics software package for education and data analysis. Palaeontologia Electronica 4: 9pp.

He, X., G. Han, Y. Lin, X. Tian, C. Xiang, Q. Tian, F. Wang and Z. He. 2012. Diversity and decomposition potential of endophytes in leaves of a Cinnamomum camphora plantation in China. Ecological Research 27: 273-284.

Hortal, J., P. A. V. Borges and C. Gaspar, 2006. Evaluating the performance of species richness estimators: sensitivity to sample grain size. Journal of Animal Ecology 75: 274-287.

Hirose, D. and T. Osono 2006. Development and seasonal variations of Lophodermium populations on Pinus thunbergii needle litter. Mycoscience 47: 242-247.

Hudson, H. J. 1968. The ecology of fungi on plant remains above the soil. New Phytologist 67: 837-874.

633

634

Hultén, E. 1965. Flora of Alaska and neighboring territories; a manual of the vascular plants.

635

636

637

638

639

640

641

642

643

644

645

646

647

648

649

650

651

652

653

654

655

656

657

658

659

660 Stanford University Press, Stanford, California, USA.

Jumpponen, A. and K. L. Jones. 2009. Massively parallel 454 sequencing indicates hyperdiverse fungal communities in temperate Quercus macrocarpa phyllosphere. New Phytologist 184: 438-448.

Katoh, K. and H. Toh. 2008. Recent developments in the MAFFT multiple sequence alignment program. Briefings in Bioinformatics 9: 286-298.

Koide, K., T. Osono and H. Takeda. 2005. Fungal succession and decomposition of Camellia japonica leaf litter. Ecological Research 20: 599-609.

Korkama-Rajala, T., M. M. Müller and T. Pennanen. 2008. Decomposition and fungi of needle litter from slow- and fast-growing Norway spruce. Microbial Ecology 56: 76-89.

Kumaresan, V. and T. S. Suryanarayanan. 2002. Endophyte assemblages in young, mature, and senescent leaves of Rhizophora apiculata: evidence for the role of endophytes in mangrove litter degradation. Fungal Diversity 9: 81-91.

Langenfeld, A., S. Prado, B. Nay, C. Cruaud, S. Lacoste, E. Bury, F. Hachette, T. Hosoya and J. Dupont. 2013. Geographic locality greatly infleucnes fungal endophyte communities in Cephalotaxus harringtonia. Fungal Biology 117: 124-136.

Liggenstoffer, A., N. Youssef, M. Couger, M. Elshahed. 2010. Phylogenetic diversity and community structure of anaerobic gut fungi (phylum Neocallimastigomycota) in ruminant and non-ruminant herbivores. ISME J. 4: 1225-1235.

661

662 Lin, Y., X. He, T. Ma, G. Han and C. Xiang. 2015. Priority colonization of Cinnamomum 663 camphora litter by endophytes affects decomposition rate, fungal community and microbial 664 activities under field conditions. Pedobiologia 58: 177-185. 
665

666

667

668

669

670

671

672

673

674

675

676

677

678

679

680

681

682

683

684

685

686

687

688

689

690

691

692

693

694

695

696

697

698

699

700

701

702

703

704

705

706

707

708

709

710

711

712

713

714

715

Lindahl, B. D., K. Ihrmark, J. Boberg, S. E. Trumbore, P. Högberg, J. Stenlid and R. D. Finlay. 2007. Spatial separation of litter decomposition and mycorrhizal nitrogen uptake in a boreal forest. New Phytologist 173: 611-620.

Magurran, A. E. 2004. Measuring biological diversity. Blackwell Publishing Ltd., Oxford, UK.

Manter, D. K. and M. G. Bakker. 2015. Estimating beta diversity for under-sampled communities using the variably weighted Odum dissimilarity index and OTUshuff. Bioinformatics 31: 34513459.

Müller, M. M., R. Valjakka, A. Suokko and J. Hantula. 2001. Diversity of endophytic fungi of single Norway spruce needles and their role as pioneer decomposers. Microbial Ecology 10:1801-1810.

Nguyen, N. H., Z. Song, S. T. Bates, S. Branco, L. Tedersoo, J. Menke, J. Schillnig and P. G. Kennedy. 2016. FUNGuild: An open annotation tool for parsing fungal community datasets by ecological guild. Fungal Ecology 20: 241-248

Oksanen, J., F. Guillaume Blanchet, R. Kindt, P. Legendre, P. R. Minchin, R. B. O'Hara, G. L. Simpson, P. Solymos, M. Henry, H. Stevens and H. Wagner. 2015. vegan: Community Ecology Package. R package version 2.3-2. https://CRAN.R-project.org/package=vegan.

Oono, R., F. Lutzoni, A. E. Arnold, L. Kaye, J. M. U'Ren, G. May and I. Carbone. 2014. Genetic variation in horizontally transmitted fungal endophytes of pine needles reveals population structure in cryptic species. American Journal of Botany 101: 1362-1374.

Osono, T. 2002. Phyllosphere fungi on leaf litter of Fagus crenata: occurrence, colonization, and succession. Canadian Journal of Botany 80: 460-469.

Osono, T. 2005. Colonization and succession of fungi during decomposition of Swida controversa leaf litter. Mycologia 97: 589-597.

Osono, T. 2006. Role of phyllosphere fungi of forest trees in the development of decomposer fungal communities and decomposition processes of leaf litter. Canadian Journal of Microbiology 52: 701-716.

Osono, T. 2007. Ecology of ligninolytic fungi associated with leaf litter decomposition. Ecological Research 22: 955-974.

Osono, T. and D. Hirose. 2009. Effects of prior decomposition of Camellia japonica leaf litter by an endophytic fungus on the subsequent decomposition by fungal colonizers. Mycoscience 50: 52-55.

Osono, T. and D. Hirose. 2011. Colonization and lignin decomposition of pine needle litter by Lophodermium pinastri. Forest Pathology 41: 156-162.

Osono, T. and H. Takeda. 2001. Organic chemical and nutrient dynamics in decomposing beech leaf litter in relation to fungal ingrowth and succession during 3-year decomposition processes in a cool temperate forest in Japan. Ecological Research 16: 649-670. 
716 Osono, T. and H. Takeda. 2006. Fungal decomposition of Abies needle and Betula leaf litter. Mycologia 98: 172-179.

Peršoh, D., J. Segert, A. Zigan and G. Rambold. 2013. Fungal community composition shifts along a leaf degradation gradient in a European beech forest. Plant Soil 362:175-186.

Porras-Alfaro, A. and P. Bayman. 2011. Hidden fungi, emergent properties: endophytes and microbiomes. Annual Review of Phytopathology 49: 291-315.

Promputtha, I., S. Lumyong, P. Lumyong, E. H. C. McKenzie and K. D. Hyde. 2002. Fungal succession on senescent leaves of Manglietia garrettii in Doi Suthep-Pui National Park, northern Thailand. Fungal Diversity 10: 89-100.

Promputtha, I., S. Lumyong, V. Dhanasekaran, E. H. C. McKenzie, K. D. Hyde and R. Jeewon. 2007. A phylogenetic evaluation of whether endophytes become saprotrophs at host senescence. Microbial Ecology 53: 579-590.

Promputtha, I., K. D. Hyde, E. H. C. McKenzie, J. F. Peberdy and S. Lumyong. 2010. Can leaf degrading enzymes provide evidence that endophytic fungi becoming saprobes? Fungal Diversity 41: 89-99.

Radford A.E., H. E. Ahles, and C. R. Bell. 1968. Manual of the vascular flora of the Carolinas. University of North Carolina Press, Chapel Hill North Carolina, USA.

Rodriguez R. J., J. F. White, A. E. Arnold and R. S. Redman. 2009. Fungal endophytes: diversity and functional roles. New Phytologist 182: 314-330.

Saunders, M., A. E. Glenn and L. M. Kohn. 2010. Exploring the evolutionary ecology of fungal endophytes in agricultural systems: using functional traits to reveal mechanisms in community processes. Evolutionary Applications 3: 525-537.

Schloss, P.D., S. L. Wescott, T. Ryabin, J. R. Hall, M. Hartmann, E. B. Hollister, R. A. Lesniewski, B. B. Oakley, D. H. Parks, C. J. Robinson, J. W. Sahl, B. Stres, G. G. Thallinger, D. J. Van Horn and C. F. Weber. 2009. Introducing mothur: open-source, platform-independent, community-supported software for describing and comparing microbial communities. Applied and Environmental Microbiology 75: 7537-7541.

Schulz, B. and C. Boyle. 2005. The endophytic continuum. Mycological Research. 109: 661686.

Sharratt, B. S. 1992. Growing season trends in the Alaskan climate record. Arctic 45: 124-127.

Šnajdr, J. T. Cajthaml, V. Valášková, V. Merhautová, M. Petránková, P. Spetz, K. Keppänen and P. Baldrian. 2011. Transformation of Quercus petraea litter: successive changes in litter chemistry are reflected in deferential enzyme activity and changes in the microbial community composition. FEMS Microbiology Ecology 75: 291-303.

Stone, J.K. 1987. Initiation and development of latent infections by Rhabdocline parkeri on Douglas-fir. Canadian Journal of Botany 65: 2614-2621. 
766 Sun, X., L.-D. Guo and K. D. Hyde. 2011. Community composition of endophytic fungi in Acer truncatum and their role in decomposition. Fungal Diversity 47: 85-95.

Sun, Y., Y. Cai, F. Yu, M. L. Farrrel, W. McKendree and W. Farmerie. 2009. ESPRIT: estimating species richness using large collections of 16S rRNA pyrosequences. Nucleic Acids Research 37(10): e76.

Swofford, D. L. 2003. PAUP*. Phylogenetic Analysis Using Parsimony (*and Other Methods). Version 4. Sinauer Associates, Sunderland, Massachusetts.

Taylor, L. R. 1978. Bates, Williams, Hutchinson-a variety of diversities. In L. A. Mound, N. Warloff [eds.], Diversity of insect faunas. Blackwell Publishing Ltd., Oxford, UK.

Tucker S. L. and M. J. Orbach. 2007. Agrobacterium-mediated transformation to create an insertion library in Magnaporthe grisea, p 57-68. In Ronald PC (ed), Methods in Molecular Biology 354: Plant-Pathogen Interactions, vol 354. Humana Press, Totowa, NJ.

Unterseher, M. and M. Schnittler. 2007. Dilution-to-extinction cultivation of leaf-inhabiting endophytic fungi in beech (Fagus sylvatica L.) - Different cultivation techniques influence fungal biodiversity assessment. Mycological Research 113: 645-654.

Unterseher, M., D. Peršoh and M. Schnittler. 2013. Leaf-inhabiting endophytic fungi of European Beech (Fagus sylvatica L.) co-occur in leaf litter but are rare on decaying wood of the same host. Fungal Diversity 60: 43-54.

Urbanová, M., J. Šnajdr and P. Baldrian. 2015. Composition of fungal and bacterial communities in forest litter and soil is largely determined by dominant trees. Soil Biology and Biochemistry 84: 53-64.

U'Ren, J. M., J. W. Dalling, R. E. Gallery, D. R. Maddison, E. C. Davis, C. M. Gibson and A. E. Arnold. 2009. Diversity and evolutionary origins of fungi associated with seeds of a neotropical pioneer tree: a case study for analyzing fungal environmental samples. Mycological Research 113: 432-449.

U'Ren, J. M., F. Lutzoni, J. Miadlikowska and A. E. Arnold. 2010. Community analysis reveals close affinities between endophytic and endolichenic fungi in mosses and lichens. Microbial Ecology 60: 340-353.

U'Ren, J. M., F. Lutzoni, J. Miadlikowska, A. Laetsch and A. E. Arnold. 2012. Host- and geographic structure of endophytic and endolichenic fungi at a continental scale. American Journal of Botany. 99: 898-914.

U'Ren, J. M., J. Riddle, J. T. Monacell, I. Carbone, J. Miadlikowska and A. E. Arnold. 2014. Tissue storage and primer selection influence pyrosequencing-based inferences of diversity and community composition of endolichenic and endophytic fungi. Molecular Ecology Resources 14: 1032-1048.

U'Ren, J. M., J. Miadlikowska, N. B. Zimmerman, J. E. Stajich, F. Lutzoni and A. E. Arnold. 2016. Contributions of North American endophytes to the phylogeny, ecology, and taxonomy of Xylariaceae (Sordariomycetes, Ascomycota). Molecular Phylogenetics and Evolution 98: 210232. 
817

818

819

820

821

822

823

824

825

826

827

828

829

830

831

832

833

834

835

836

837

838

839

840

841

842

843
Vilgalys, R. and M. Hester. 1990. Rapid genetic identification and mapping of enzymatically amplified ribosomal DNA from several Cryptococcus species. Journal of Bacteriology 172: 4238-4246.

Voříšková, J. and P. Baldrian. 2013. Fungal community on decomposing leaf litter undergoes rapid successional changes. ISME Journal 7: 477-486.

Wang, Q, G. M. Garrity, J. M. Tiedje and J. R. Cole. 2007. Naïve bayesian classifier for rapid assignment of rRNA sequences into the new bacterial taxonomy. Applied and Environmental Microbiology 73: 5261-5267.

White, T. J., T. Bruns, S. Lee and J. T. 1990. Amplification and direct sequencing of fungal ribosomal RNA genes for phylogenetics. In M. A. Innis, D. H. Gelfand, J. J. Sninsky, T. J. White [eds.] PCR Protocols: a guide to methods and applications. Academic Press, San Diego, California, USA.

Yuan, Z.-L., L.-B. Rao, Y.-C. Chen, C.-L. Zhang and Y.-G. Wu. 2011. From pattern to process: species and functional diversity in fungal endophytes of Abies beshanzuensis. Fungal Biology 115: 197-213.

Yuan, Z. and L. Chen. 2014. The role of endophytic fungal individuals and communities in the decomposition of Pinus massoniana needle litter. PLoS One 9(8): e105911.

Zimmerman, N. B. and P. M. Vitousek. 2012. Fungal endophyte communities reflect environmental structuring across a Hawaiian landscape. Proceedings of the National Academy of Sciences USA 109: 13022-13027. 
Table 1. Isolation frequency, richness and diversity of cultivable fungi from the interior of surface-sterilized leaves, including living leaves (i.e., endophytic fungi), fungi from dead leaves in canopies of woody plants (DLF), and fungi from leaf litter (LLF), from 18 plant species in five sites across North America. Site abbreviations match those in U'Ren et al. (2012): (AZC: Chiricahua Mountains, Arizona; NCH: Highlands Biological Station,

North Carolina; FLA: Archbold Biological Station, Florida; AKE: Eagle Summit, Alaska; AKN: Nome, Alaska).

\begin{tabular}{|c|c|c|c|c|c|c|c|c|c|c|c|}
\hline Site & Host family & Host species* & $\begin{array}{l}\text { Fungal } \\
\text { type }\end{array}$ & $\begin{array}{l}\text { Leaf } \\
\text { segments } \\
\star *\end{array}$ & $\begin{array}{l}\text { Isolates } \\
\text { recovered }\end{array}$ & $\begin{array}{l}\text { Isolation } \\
\text { frequency/ } \\
\text { microsite } \pm \\
\text { SD }\end{array}$ & $\begin{array}{l}\text { Isolates } \\
\text { sequence } \\
\text { d (\%) }\end{array}$ & $\begin{array}{l}\text { Basidio- } \\
\text { mycota } \\
\text { sequenc } \\
\text { es }\end{array}$ & $\begin{array}{l}\text { Ascomy } \\
\text { cota } \\
\text { sequenc } \\
\text { es } \\
\text { (Putative } \\
\text { species) }\end{array}$ & $\begin{array}{l}\text { Ascomycota } \\
\text { ACE }(95 \% \mathrm{Cl})\end{array}$ & $\begin{array}{l}\text { Fisher's } \\
\text { alpha }\end{array}$ \\
\hline \multirow[t]{3}{*}{ AZC } & Cupressaceae & $\begin{array}{l}\text { Juniperus } \\
\text { deppeana }\end{array}$ & endophyte & 144 & 22 & $0.15 \pm 0.12$ & $19(86 \%)$ & 0 & $19(10)$ & $27.2(15.9,16.3)$ & 8.5 \\
\hline & & & DLF & 141 & 87 & $0.62 \pm 0.18$ & $82(94 \%)$ & 0 & $82(24)$ & $50.5(36.2,81.5)$ & 11.4 \\
\hline & & & LLF & 144 & 43 & $0.30 \pm 0.09$ & $37(86 \%)$ & 0 & 37 (18) & $22.8(19.1,38.0)$ & 13.8 \\
\hline \multirow[t]{3}{*}{$A Z C$} & Pinaceae & $\begin{array}{l}\text { Pinus arizonica } \\
\text { var. arizonica }\end{array}$ & endophyte & 144 & 9 & $0.06 \pm 0.02$ & $9(100 \%)$ & 0 & $9(2)$ & $3.8(2.2,17.0)$ & 0.8 \\
\hline & & & DLF & 144 & 36 & 0.250 .40 & $31(86 \%)$ & 0 & $31(3)$ & $\mathrm{N} / \mathrm{A}$ & 0.8 \\
\hline & & & LLF & 143 & 57 & $0.40 \pm 0.35$ & $55(96 \%)$ & 0 & $55(8)$ & $23.2(13.5,49.9)$ & 2.6 \\
\hline \multirow[t]{3}{*}{$A Z C$} & Pinaceae & $\begin{array}{l}\text { Pseudotsuga } \\
\text { menziesii }\end{array}$ & endophyte & 144 & 21 & $0.15 \pm 0.22$ & $16(76 \%)$ & 0 & $16(3)$ & $4.0(3.2,7.1)$ & 1.1 \\
\hline & & & DLF & 142 & 29 & $0.20 \pm 0.21$ & $19(66 \%)$ & 0 & $19(3)$ & NA & 1.0 \\
\hline & & & LLF & 144 & 29 & $0.20 \pm 0.03$ & $25(86 \%)$ & 0 & $25(9)$ & $20.7(12.7,46.0)$ & 5.0 \\
\hline \multirow[t]{3}{*}{$A Z C$} & Fagaceae & Quercus rugosa & endophyte & 130 & 0 & 0 & N/A & $\mathrm{N} / \mathrm{A}$ & $\mathrm{N} / \mathrm{A}$ & N/A & $\mathrm{N} / \mathrm{A}$ \\
\hline & & & DLF & 144 & 34 & $0.24 \pm 0.39$ & $32(97 \%)$ & 0 & $32(7)$ & $\mathrm{N} / \mathrm{A}$ & 2.8 \\
\hline & & & LLF & 143 & 29 & $0.20 \pm 0.18$ & $27(90 \%)$ & 0 & $27(7)$ & $9.5(7.3,25.3)$ & 3.1 \\
\hline \multirow[t]{3}{*}{$\mathrm{NCH}$} & Pinaceae & Pinus strobus & endophyte & 114 & 14 & $0.14 \pm 0.11$ & $13(93 \%)$ & 0 & $13(6)$ & $30.6(15.1,72.5)$ & 4.3 \\
\hline & & & DLF & 144 & 63 & $0.44 \pm 0.31$ & $61(97 \%)$ & 1 & $60(9)$ & $\begin{array}{l}30.0(10.6 \\
277.5)\end{array}$ & 2.9 \\
\hline & & & LLF & 144 & 62 & $0.43 \pm 0.28$ & $49(79 \%)$ & 0 & $49(16)$ & $25.9(18.5,55.2)$ & 8.3 \\
\hline \multirow[t]{3}{*}{$\mathrm{NCH}$} & Pinaceae & Tsuga canadensis & endophyte & 144 & 54 & $0.38 \pm 0.26$ & $49(91 \%)$ & 0 & $49(13)$ & $19(16.5,23.4)$ & 5.8 \\
\hline & & & DLF & 144 & 53 & $0.37 \pm 0.39$ & $42(79 \%)$ & 0 & $42(24)$ & $\begin{array}{l}162.2(108.9 \\
248.8)\end{array}$ & 23.3 \\
\hline & & & LLF & 144 & 123 & $0.85 \pm 0.08$ & $95(77 \%)$ & 2 & $93(26)$ & $48.0(35.8,75.4)$ & 12.0 \\
\hline \multirow[t]{2}{*}{$\mathrm{NCH}$} & Ericaceae & Kalmia latifolia $L$. & endophyte & 144 & 29 & $0.20 \pm 0.31$ & $29(100 \%)$ & 0 & $29(6)$ & $9.8(7.6,15.0)$ & 2.3 \\
\hline & & & DLF & 144 & 71 & $0.49 \pm 0.34$ & $65(92 \%)$ & 0 & $65(14)$ & $43.4(26.6,82.4)$ & 5.5 \\
\hline
\end{tabular}




\begin{tabular}{|c|c|c|c|c|c|c|c|c|c|c|c|}
\hline & & & LLF & 144 & 114 & $0.79 \pm 0.15$ & $91(80 \%)$ & 0 & $91(18)$ & $\begin{array}{l}66.1(41.3 \\
117.5)\end{array}$ & 6.7 \\
\hline \multirow[t]{3}{*}{$\mathrm{NCH}$} & Fagaceae & Quercus montana & endophyte & 144 & 60 & $0.42 \pm 0.33$ & 57 (95\%) & 0 & $57(6)$ & $25.2(11.5,73.1)$ & 1.7 \\
\hline & & & DLF & 144 & 58 & $0.40 \pm 0.42$ & $47(81 \%)$ & 0 & $47(12)$ & $\begin{array}{l}170.2(102.8 \\
287.5)\end{array}$ & 5.2 \\
\hline & & & LLF & 144 & 46 & $0.32 \pm 0.17$ & $27(59 \%)$ & 0 & $27(13)$ & $38.9(23.6,76.4)$ & 9.9 \\
\hline \multirow[t]{3}{*}{ FLA } & Pinaceae & Pinus ellottii & endophyte & 144 & 138 & $0.96 \pm 0.04$ & 130 (94\%) & 57 & $73(32)$ & $\begin{array}{l}60.6(42.5 \\
109.9)\end{array}$ & 21.7 \\
\hline & & & DLF & 144 & 102 & $0.71 \pm 0.29$ & $84(82 \%)$ & 3 & $81(32)$ & $\begin{array}{l}126.6(82.0 \\
210.9)\end{array}$ & 19.5 \\
\hline & & & LLF & 144 & 100 & $0.69 \pm 0.23$ & $85(85 \%)$ & 0 & $85(28)$ & $\begin{array}{l}53.0(36.6 \\
100.8)\end{array}$ & 14.6 \\
\hline \multirow[t]{3}{*}{ FLA } & Pinaceae & Pinus clausa & endophyte & 144 & 52 & $0.36 \pm 0.07$ & $47(90 \%)$ & 29 & $18(11)$ & $\begin{array}{l}111.1(59.3, \\
218.8)\end{array}$ & 12.0 \\
\hline & & & DLF & 144 & 88 & $0.61 \pm 0.33$ & $75(85 \%)$ & 2 & $73(30)$ & $\begin{array}{l}88.9(61.5 \\
140.2)\end{array}$ & 19.0 \\
\hline & & & LLF & 144 & 104 & $0.72 \pm 0.10$ & $88(85 \%)$ & 3 & $85(23)$ & $38.0(27.6,71.9)$ & 10.4 \\
\hline \multirow[t]{3}{*}{ FLA } & Arecaceae & Serenoa repens & endophyte & 144 & 65 & $0.45 \pm 0.40$ & $58(89 \%)$ & 17 & $41(10)$ & $17.4(12.1,35.9)$ & 4.2 \\
\hline & & & DLF & 144 & 81 & $0.56 \pm 0.21$ & $56(69 \%)$ & 1 & $55(33)$ & $\begin{array}{l}\text { 154.3 (105.4, } \\
236.4)\end{array}$ & 34.8 \\
\hline & & & LLF & 144 & 73 & $0.51 \pm 0.17$ & 58 (79\%) & 2 & $56(39)$ & $70.5(62.3,81.5)$ & 57.0 \\
\hline \multirow[t]{3}{*}{ FLA } & Fagaceae & Quercus inopina & endophyte & 144 & 80 & $0.56 \pm 0.25$ & $51(64 \%)$ & 1 & $50(19)$ & $\begin{array}{l}89.0(55.7 \\
152.6)\end{array}$ & 11.2 \\
\hline & & & DLF & 144 & 95 & $0.66 \pm 0.50$ & $67(71 \%)$ & 0 & $67(28)$ & $\begin{array}{l}\text { 119.4 (81.4, } \\
184.5)\end{array}$ & 18.1 \\
\hline & & & LLF & 144 & 100 & $0.69 \pm 0.35$ & $72(72 \%)$ & 0 & $72(41)$ & $\begin{array}{l}\text { 153.6 (107.1, } \\
232.9)\end{array}$ & 39.5 \\
\hline \multirow[t]{3}{*}{ AKE } & Pinaceae & Picea glauca & endophyte & 144 & 8 & $0.06 \pm 0.03$ & $7(88 \%)$ & 1 & $6(6)$ & $\mathrm{N} / \mathrm{A}$ & N/A \\
\hline & & & DLF & 144 & 43 & $0.30 \pm 0.16$ & $36(84 \%)$ & 0 & $36(17)$ & $48.8(31.3,87.7)$ & 12.6 \\
\hline & & & LLF & 144 & 77 & $0.53 \pm 0.32$ & $64(83 \%)$ & 1 & $63(29)$ & $51.1(36.9,91.1)$ & 20.8 \\
\hline \multirow[t]{3}{*}{ AKE } & Betulaceae & Betula nana & endophyte & 144 & 2 & $0.01 \pm 0.01$ & $2(100 \%)$ & 0 & $2(2)$ & $\mathrm{N} / \mathrm{A}$ & $\mathrm{N} / \mathrm{A}$ \\
\hline & & & DLF & 144 & 10 & $0.07 \pm 0.05$ & $10(100 \%)$ & 0 & $10(6)$ & $\begin{array}{l}65.7(28.8 \\
162.5)\end{array}$ & 6.3 \\
\hline & & & LLF & 144 & 37 & $0.26 \pm 0.25$ & $36(97 \%)$ & 0 & $36(18)$ & $48.0(30.9,88.0)$ & 14.3 \\
\hline \multirow[t]{3}{*}{ AKE } & Salicaceae & Salix pulchra & endophyte & 144 & 3 & $0.02 \pm 0.02$ & $2(67 \%)$ & 0 & $2(2)$ & N/A & N/A \\
\hline & & & DLF & 144 & 15 & $0.10 \pm 0.04$ & $12(80 \%)$ & 0 & $12(9)$ & $\begin{array}{l}26.8(12.3 \\
104.3)\end{array}$ & 16.4 \\
\hline & & & LLF & 144 & 19 & $0.13 \pm 0.10$ & $13(68 \%)$ & 0 & $13(9)$ & $14.6(12.9,17.1)$ & 12.9 \\
\hline
\end{tabular}




\begin{tabular}{|c|c|c|c|c|c|c|c|c|c|c|c|}
\hline \multirow[t]{3}{*}{ AKN } & Pinaceae & Picea glauca* & endophyte & 144 & 68 & $0.47 \pm 0.37$ & $65(96 \%)$ & 0 & $65(8)$ & $9.2(8.1,18.8)$ & 2.4 \\
\hline & & & DLF & 144 & 75 & $0.52 \pm 0.15$ & $60(80 \%)$ & 0 & $60(20)$ & $42.0(29.6,70.1)$ & 10.5 \\
\hline & & & LLF & 144 & 35 & $0.24 \pm 0.23$ & $32(91 \%)$ & 5 & $27(11)$ & $17.9(12.4,45.0)$ & 6.9 \\
\hline \multirow[t]{3}{*}{ AKN } & Salicaceae & Salix pulchra & endophyte & 144 & 0 & 0 & $\mathrm{~N} / \mathrm{A}$ & $\mathrm{N} / \mathrm{A}$ & $\mathrm{N} / \mathrm{A}$ & $\mathrm{N} / \mathrm{A}$ & N/A \\
\hline & & & DLF & 144 & 0 & 0 & NA & $\mathrm{N} / \mathrm{A}$ & N/A & $\mathrm{N} / \mathrm{A}$ & N/A \\
\hline & & & LLF & 144 & 1 & $0.01 \pm 0.01$ & 0 & N/A & $\mathrm{N} / \mathrm{A}$ & $\mathrm{N} / \mathrm{A}$ & N/A \\
\hline \multirow[t]{3}{*}{ AKN } & Betulaceae & Betula nana & endophyte & 144 & 0 & 0 & $\mathrm{~N} / \mathrm{A}$ & $\mathrm{N} / \mathrm{A}$ & $\mathrm{N} / \mathrm{A}$ & $\mathrm{N} / \mathrm{A}$ & N/A \\
\hline & & & DLF & 144 & 2 & $0.01 \pm 0.02$ & $1(50 \%)$ & 0 & $1(1)$ & $\mathrm{N} / \mathrm{A}$ & N/A \\
\hline & & & LLF & 144 & 2 & $0.01 \pm 0.01$ & $1(50 \%)$ & 0 & $1(1)$ & $\mathrm{N} / \mathrm{A}$ & $\mathrm{N} / \mathrm{A}$ \\
\hline Total & & & & 7725 & 2618 & $0.34 \pm 0.26$ & $\begin{array}{l}2189 \\
(84 \%)\end{array}$ & 125 & $\begin{array}{l}2064 \\
(306)\end{array}$ & $\begin{array}{l}437.8 \text { (395.7, } \\
499.9)\end{array}$ & 99.3 \\
\hline
\end{tabular}

$8 \overline{44}$

845

846

847

* Hosts were collected approximately $60 \mathrm{~km}$ east of Nome, in Council, AK (the nearest site that contains trees).

${ }^{* *}$ We initially sampled 144 leaf segments from each host species in each site (i.e., 48 per microsite for three microsites), but a small number were lost to contamination, overgrowth, and desiccation. 
Table 2. Summary of isolation frequency, richness and diversity of endophytic fungi, fungi from dead leaves in tree canopies (DLF), and fungi from leaf litter (LLF) in five North American sites.

\begin{tabular}{|c|c|c|c|c|c|c|c|c|c|c|c|}
\hline & Site & $\begin{array}{l}\text { Host } \\
\text { species } \\
\text { (yielding } \\
\text { cultures) }\end{array}$ & Isolates & $\begin{array}{l}\text { Isolation } \\
\text { frequency } \pm \\
\text { SD* }^{*}\end{array}$ & $\begin{array}{l}\text { Isolates } \\
\text { sequenced } \\
(\%)\end{array}$ & $\begin{array}{l}\text { Basidio- } \\
\text { mycota } \\
\text { sequences }\end{array}$ & $\begin{array}{l}\text { Asco- } \\
\text { mycota } \\
\text { sequences }\end{array}$ & $\begin{array}{l}\text { Ascomycota } \\
\text { putative species } \\
(95 \% \mathrm{Cl})\end{array}$ & $\begin{array}{l}\text { Richness } \\
\text { estimates } \\
\text { (Bootstrap, } \\
\text { ACE) }\end{array}$ & $\begin{array}{l}\text { Fisher's } \\
\text { alpha } \\
\text { (FA) }\end{array}$ & $\begin{array}{l}\text { Mean } \\
\text { FA/host } \\
\text { species } \pm \\
\text { SD }\end{array}$ \\
\hline \multirow{6}{*}{ 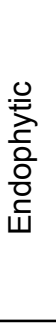 } & $A Z C$ & $4(3)$ & 52 & $0.09 \pm 0.07^{a b}$ & $44(85 \%)$ & 0 & 44 & $15(10.9,19.1)$ & $17.2,17.9$ & 8 & $3.5 \pm 4.4$ \\
\hline & $\mathrm{NCH}$ & $4(4)$ & 157 & $0.28 \pm 0.14^{\mathrm{ab}}$ & $148(94 \%)$ & 0 & 148 & $27(25.1,28.9)$ & $29.6,29.3$ & 9.7 & $3.5 \pm 1.9$ \\
\hline & FLA & $4(4)$ & 335 & $0.58 \pm 0.26^{a}$ & $286(85 \%)$ & 104 & 182 & $60(51.7,68.3)$ & $71.7,95.4$ & 31.2 & $12.3 \pm 7.2$ \\
\hline & AKE & $3(3)$ & 13 & $0.03 \pm 0.02^{b}$ & $11(85 \%)$ & 1 & 10 & $10(4.5,15.6)$ & $13.5,55.0$ & N/A & $\mathrm{N} / \mathrm{A}$ \\
\hline & AKN & $3(1)$ & 68 & $0.16 \pm 0.27^{\mathrm{ab}}$ & $65(96 \%)$ & 0 & 65 & $8(5.5,10.5)$ & $8.9,10.0$ & 2.4 & 2.4 \\
\hline & Total & $18(15)$ & 625 & $0.24 \pm 0.26^{\mathrm{B}}$ & $554(89 \%)$ & 105 & 449 & $108(99.6,116.1)$ & $122.6,128.5$ & 45.1 & $6.3 \pm 6.2^{\mathrm{B}}$ \\
\hline \multirow{6}{*}{ 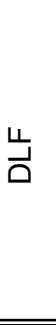 } & AZC & $4(4)$ & 186 & $0.33 \pm 0.19^{a b}$ & $164(88 \%)$ & 0 & 164 & $33(28.3,37.7)$ & $37.8,42.9$ & 12.4 & $4.0 \pm 5.0^{b}$ \\
\hline & $\mathrm{NCH}$ & $4(4)$ & 245 & $0.43 \pm 0.05^{\mathrm{ab}}$ & $215(88 \%)$ & 1 & 214 & $50(42.1,57.9)$ & $57.6,67.1$ & 20.5 & $9.22 \pm 9.4^{\mathrm{ab}}$ \\
\hline & FLA & $4(4)$ & 366 & $0.64 \pm 0.06^{a}$ & $282(77 \%)$ & 6 & 276 & $81(69.1,92.9)$ & $95.9,122.3$ & 38.6 & $22.9 \pm 8.0^{a}$ \\
\hline & AKE & $3(2)$ & 68 & $0.16 \pm 0.12^{b}$ & $58(85 \%)$ & 0 & 58 & $25(18.7,31.3)$ & $30.1,38.6$ & 16.7 & $11.8 \pm 5.1^{\mathrm{ab}}$ \\
\hline & AKN & $3(3)$ & 77 & $0.18 \pm 0.30^{\mathrm{b}}$ & $61(79 \%)$ & 0 & 61 & $21(16.3,25.7)$ & $25.1,33.0$ & 11.3 & 10.5 \\
\hline & Total & $18(17)$ & 942 & $0.36 \pm 0.23^{A}$ & $780(83 \%)$ & 7 & 773 & $182(168.7,195.3)$ & $211,240.9$ & 75.1 & $11.9 \pm 9.5^{\mathrm{AB}}$ \\
\hline \multirow{6}{*}{ 岌 } & $A Z C$ & $4(4)$ & 158 & $0.28 \pm 0.09 \mathrm{ab}$ & $144(91 \%)$ & 0 & 144 & $35(29.7,40.2)$ & $40.8,46.4$ & 14.7 & $6.1 \pm 5.2^{b}$ \\
\hline & $\mathrm{NCH}$ & $4(4)$ & 345 & $0.60 \pm 0.26^{a}$ & $262(76 \%)$ & 2 & 260 & $58(49.8,66.3)$ & $65,67.0$ & 23.2 & $9.2 \pm 2.3^{\mathrm{ab}}$ \\
\hline & FLA & $4(4)$ & 377 & $0.66 \pm 0.10^{a}$ & $303(80 \%)$ & 5 & 298 & $93(84.1,101.9)$ & $109.3,125.0$ & 46.4 & $30.4 \pm 21.9^{a}$ \\
\hline & AKE & $3(3)$ & 133 & $0.31 \pm 0.20^{\mathrm{ab}}$ & $113(85 \%)$ & 1 & 112 & $41(33.3,48.7)$ & $49.6,70.7$ & 23.3 & $16 \pm 4.2^{\mathrm{ab}}$ \\
\hline & AKN & $3(3)$ & 38 & $0.09 \pm 0.13^{b}$ & $33(90 \%)$ & 5 & 28 & $12(9.7,14.3)$ & $14.1,15.0$ & 8 & 6.9 \\
\hline & Total & $18(18)$ & 1051 & $0.41 \pm 0.26^{\mathrm{A}}$ & $855(81 \%)$ & 13 & 842 & $195(179.1,210.9)$ & $226.9,266.3$ & 79.6 & $14.9 \pm 14.2^{\mathrm{A}}$ \\
\hline
\end{tabular}

849 * Different letters represent significant differences $(P<0.05)$ in isolation frequency among sites for each leaf type (lowercase;

850 endophytic: $A N O V A F_{4,10}=7.31, P=0.0051$; DLF: ANOVA $F_{4,12}=3.30, P=0.0482 ;$ LLF: $\left.A N O V A F_{4,13}=7.41, P=0.0025\right)$ based on

851 post-hoc Tukey's HSD comparisons and among leaf types (uppercase: linear contrasts following ANOVA on residuals after test for

852 site effects; $F_{1.47}=4.11, P=0.0484$ ).

$853{ }^{* *}$ Different letters represent significant differences $(P<0.05)$ in diversity per-host-species among leaf types (uppercase; ANOVA on 854 residuals following test for site effects, $F_{4,39}=11.56, P<0.0001$ ) and among sites for DLF and LLF (lowercase; DLF: ANOVA on log

$855 \mathrm{FA}, \mathrm{F}_{3,11}=5.35 \mathrm{P}=0.0162$; LLF: ANOVA on log $F A, F_{3,11}=5.27 \mathrm{P}=0.0170$ ), but endophytic fungi only approached significance

856 (ANOVA on log $F A, F_{2,8}=3.87 P=0.0667$ ). 
Table 3. Statistical tests of isolation frequency and diversity in multiple regression models.

\begin{tabular}{|c|c|c|c|c|c|c|}
\hline & \multicolumn{3}{|c|}{ Isolation frequency $\left(R^{2}=0.73, P<0.0001\right)$} & \multicolumn{3}{|c|}{ Diversity $\left(R^{2}=0.80, P<0.0001\right)$} \\
\hline & DF & $\mathbf{F}$ & $\mathbf{P}$ & DF & $\mathbf{F}$ & $\mathbf{P}$ \\
\hline \multicolumn{7}{|c|}{ Explanatory variables* } \\
\hline Site & 4 & 7.07 & 0.0002 & 4 & 20.18 & $<0.0001$ \\
\hline Host family & 6 & 5.15 & 0.0006 & 6 & 4.8 & 0.0014 \\
\hline Leaf type & 2 & 4.52 & 0.0174 & 2 & 10.76 & 0.0003 \\
\hline \multicolumn{7}{|l|}{ Leaf type $e^{* *}$} \\
\hline Endo vs. DLF & 1 & 5.46 & 0.0250 & 1 & 9.53 & 0.0042 \\
\hline Endo vs. LLF & 1 & 8.19 & 0.0069 & 1 & 21.34 & $<0.0001$ \\
\hline DLF vs. LLF & 1 & 0.29 & 0.5943 & 1 & 2.9 & 0.0986 \\
\hline
\end{tabular}

${ }^{*}$ Explanatory variables: Effect test of site, host family and leaf type.

**Leaf type: Least-squares means contrasts, pairwise comparison among endophytes, DLF, and LLF. 
Table 4. Results of PERMANOVA analysis of the Morisita-Horn dissimilarities for fungal OTU community structure (DF = degrees of freedom; $S S=$ sum of squares; $M S=$ mean sum of squares; $F$ = pseudo- $\mathrm{F}$ by permutation).

\begin{tabular}{|c|c|c|c|c|c|c|}
\hline \multicolumn{7}{|c|}{ Blocks: Site (1000 permutations) } \\
\hline & DF & SS & MS & $\mathbf{F}$ & $\mathbf{R}^{2}$ & $\mathbf{P}$ \\
\hline Host species & 11 & 17.978 & 1.634 & 5.546 & 0.431 & 0.001 \\
\hline Leaf type & 2 & 1.372 & 0.686 & 2.328 & 0.033 & 0.001 \\
\hline Residuals & 78 & 22.398 & 0.295 & & 0.537 & \\
\hline Total & 89 & 41.748 & & & 1.000 & \\
\hline \multicolumn{7}{|c|}{ Blocks: Site; Plots: Host species (200 permutations) } \\
\hline & DF & SS & MS & $\mathbf{F}$ & $\mathbf{R}^{2}$ & $\mathbf{P}$ \\
\hline Leaf type & 2 & 1.446 & 0.723 & 1.560 & 0.035 & 0.005 \\
\hline Residuals & 87 & 40.303 & 0.463 & & 0.965 & \\
\hline Total & 89 & 41.748 & & & 1.000 & \\
\hline
\end{tabular}


Table 5. In vitro cellulolytic activity and growth on cellulose, lignin, and pectin for 17 representative isolates of OTU found only in living (i.e., endophytes) or non-living leaves (i.e., DLF/LLF).

\begin{tabular}{|c|c|c|c|c|c|c|c|c|c|c|}
\hline $\begin{array}{l}\text { Isolate } \\
\text { Name }\end{array}$ & $\begin{array}{l}95 \% \text { ITS- } \\
\text { partial } \\
\text { LSU } \\
\text { OTU }\end{array}$ & $\begin{array}{l}\text { Substrate } \\
\text { Type }\end{array}$ & $\begin{array}{l}\text { Isolat } \\
\text { es in } \\
\text { OTUt }\end{array}$ & Sites $\uparrow$ & $\begin{array}{l}\text { Plant host } \\
\text { species } \\
\text { (families) } \dagger\end{array}$ & Taxonomytt & $\begin{array}{l}\text { Mean } \pm \text { SD } \\
\text { growth rate } \\
\text { on cellulose } \\
\text { medium } \\
\text { (mm/day) }\end{array}$ & $\begin{array}{l}\text { Mean } \pm \text { SD } \\
\text { growth rate } \\
\text { (mm/day) on } \\
\text { lignin medium }\end{array}$ & $\begin{array}{l}\text { Mean } \pm \text { SD } \\
\text { growth rate } \\
\text { (mm/day) on } \\
\text { pectin medium }\end{array}$ & $\begin{array}{l}\text { Mean } \pm \text { SD } \\
\text { cellulolytic } \\
\text { activity/colony } \\
\text { diameter }(\mathrm{mm})\end{array}$ \\
\hline NC0075 & 403 & Living & 26 & 1 & $2(2)$ & Dothideomycetes (Phyllosticta*) & $10.7 \pm 1.1$ & $7.2 \pm 1.0$ & $25.0 \pm 3.1$ & $22.0 \pm 6.6$ \\
\hline NC0101 & 404 & Living & 6 & 1 & $2(2)$ & $\begin{array}{l}\text { Dothideomycetes (Phyllosticta*) } \\
\text { Dothideomycetes }\end{array}$ & $11.4 \pm 2.0$ & $7.8 \pm 0.4$ & $22.1 \pm 3.8$ & $40.0 \pm 16.8$ \\
\hline FL0319 & 261 & Living & 7 & 1 & $1(1)$ & (Ochrocladosporium) & $17.1 \pm 0.3$ & $10.4 \pm 0.3$ & $14.5 \pm 0.4$ & $45.3 \pm 1.5$ \\
\hline FL1985 & 366 & Non-living & 13 & 1 & $2(2)$ & Dothideomycetes (Penidiella*) & $7.3 \pm 0.3$ & $6.2 \pm 0.5$ & $9.6 \pm 0.6$ & $49.0 \pm 6.0$ \\
\hline FL0303 & 259 & Living & 12 & 1 & $1(1)$ & $\begin{array}{l}\text { Dothideomycetes (Mycosphaerella*) } \\
\text { Dothideomycetes (Teratosphaeria }\end{array}$ & $26.7 \pm 0.4$ & $26.9 \pm 1.6$ & $28.3 \pm 0.8$ & $15.3 \pm 4.0$ \\
\hline FL1704 & 353 & Non-living & 9 & 1 & $2(1)$ & marasasii) & $10.2 \pm 5.8$ & $6.6 \pm 0.4$ & $8.5 \pm 0.1$ & $82.0 \pm 42.5$ \\
\hline AK1907 & 118 & Non-living & 16 & 3 & $4(1)$ & Leotiomycetes (Hyalodendriella*) & $11.3 \pm 0.2$ & $11.7 \pm 0.9$ & $12.6 \pm 0.3$ & $46.0 \pm 2.0$ \\
\hline FL2076 & 360 & Non-living & 9 & 1 & $2(2)$ & Leotiomycetes (Rhytisma*) & $6.2 \pm 1.4$ & $6.8 \pm 0.5$ & $6.2 \pm 1.6$ & $145.7 \pm 38.8$ \\
\hline FL2145 & 355 & Non-living & 7 & 1 & $1(1)$ & Leotiomycetes (Rhytisma*) & $7.0 \pm 0.8$ & $4.1 \pm 1.3$ & $23.1 \pm 1.2$ & $167.7 \pm 28.9$ \\
\hline AZO245 & 163 & Non-living & 7 & 1 & $2(2)$ & Pezizomycetes (Strobiloscypha*) & $13.2 \pm 0.5$ & $5.9 \pm 0.4$ & $31.3 \pm 3.3$ & $40.3 \pm 4.6$ \\
\hline FL0231 & 253 & Living & 7 & 2 & $5(2)$ & Sordariomycetes (Lecythophora*) & $20.5 \pm 0.6$ & $25.9 \pm 1.1$ & $22.8 \pm 1.0$ & $0.0 \pm 0.0$ \\
\hline NC0063 & 406 & Living & 7 & 1 & $4(3)$ & $\begin{array}{l}\text { Sordariomycetes (Eutypa*) } \\
\text { Sordariomycetes ( Tubakia }\end{array}$ & $25.2 \pm 1.3$ & $21.7 \pm 0.6$ & $21.0 \pm 0.3$ & $28.3 \pm 4.5$ \\
\hline NC0012 & 399 & Living & 12 & 1 & $1(1)$ & seoraksanensis)) & $9.0 \pm 0.2$ & $20.3 \pm 1.2$ & $105.0 \pm 4.4$ & $116.7 \pm 4.9$ \\
\hline FL2151 & 352 & Non-living & 31 & 1 & $4(3)$ & Sordariomycetes (Magnaporthe*) & $24.4 \pm 0.3$ & $20.2 \pm 0.2$ & $21.2 \pm 0.5$ & $0.0 \pm 0.0$ \\
\hline NC1320 & 378 & Non-living & 6 & 2 & $2(2)$ & Sordariomycetes (Fusarium) & $81.0 \pm 4.4$ & $55.2 \pm 2.9$ & $91.0 \pm 1.7$ & $3.0 \pm 0.0$ \\
\hline FL1642 & 170 & Non-living & 13 & 3 & $3(1)$ & Sordariomycetes (Polyscytalum) & $17.8 \pm 1.3$ & $6.9 \pm 1.1$ & $21.9 \pm 2.4$ & $39.0 \pm 5.6$ \\
\hline NC0068 & 263 & Living & 13 & 2 & $2(2)$ & Sordariomycetes (Collectotrichum ${ }^{*}$ ) & $86.3 \pm 0.6$ & $66.7 \pm 0.8$ & $91.3 \pm 0.6$ & $0.0 \pm 0.0$ \\
\hline
\end{tabular}

862

863 † Totals include fungi isolated from lichens and plants as part of a larger study on endophytic and endolichenic fungi (U'Ren et al.,

864 2012).

865 t† Taxonomic information is based on queries of UNITE database using the RDP Bayesian classifier (see methods). However, when

866 matches to the UNITE database lacked genus and species information (e.g., the species hypothesis for FL1985 is Capnodiales sp.),

867 taxonomic information is estimated based on a BLASTn query of the NCBI nr database (indicated with an *). 


\section{Figure Legends}

873

874 Figure 1. Species accumulation curves (Mao Tau), 95\% confidence intervals, and bootstrap

875 estimates of richness based on ITS-partial LSU rDNA for (A) 449 isolates of endophytic fungi;

876 (B) 773 isolates of fungi from senesced leaves in plant canopies (dead leaf fungi, DLF); and (C)

877842 isolates of fungi from leaf litter (leaf litter fungi, LLF) in five sites.

878

879 Figure 2. (A) Proportion of isolates representing orders of Pezizomycotina as a function of 880 site/leaf type. Sequences from AKE (Eagle Summit, Alaska) and AKN (Nome, Alaska) were 881 pooled for this analysis (AK). (B) Unweighted pair-group average (UPGMA) dendrogram 882 showing hierarchical clustering of endophytes (Endo), DLF, and LLF from each site (AZC:

883 Chiricahua Mountains, Arizona; NCH: Highlands Biological Station, North Carolina; FLA:

884 Archbold Biological Station, Florida; AK: see above). Bootstrap values are based on 10,000

885 bootstrap replicates. Host individuals/leaf type with $<4$ sequences and singleton OTU were 886 excluded from hierarchical clustering analysis.

887

888 Figure 3. Pairwise community similarity among different leaf types as a function of site.

889 Similarity is measured as $1-D_{\text {wodum }}$, as calculated in OTUshuff using 1000 Monte Carlo

890 iterations. Similarity was assessed at different alpha weighting factors (i.e., when $\alpha=1, D_{\text {wOdum }}$

891 is equal to $D_{\text {Odum; }}$ when $\alpha<1$, the influence of abundant taxa will be down-weighted; and when $\alpha$

$892>1$, the influence of low abundance taxa will be down-weighted). Low sample size of

893 endophytes precluded comparisons of endophyte and DLF/LLF at AKE.

894

895 Figure 4. Heat map showing the distribution of 104 putative species (based on 95\% rDNA

896 sequence similarity; OTU with $<5$ isolates were excluded) of endophytic, dead leaf fungi (DLF),

897 and leaf litter fungi (LLF) from plants in five North American sites. Species abundance on each 
898 leaf type is shown as the percentage of the total number of isolates of that species. Taxonomy 899 was estimated for each species using the Ribosomal Database Project naïve Bayesian classifier 900 with the UNITE ITS database. The lowest level of taxonomy supported by $>80 \%$ confidence is 901 shown (classes are abbreviated as Sordariomycetes (S), Leotiomycetes (L), Eurotiomycetes

902 (E), Dothideomycetes (D), Pezizomycetes (P), or not available (NA)). Statistical support for each 903 assignment is given after the dash. Taxa are ordered according to their abundance as 904 endophytes or LLF.

905

906 Figure 5. Normalized in vivo cellulolytic activity (mean activity/colony diameter) and growth 907 (mean colony diameter/day) of 17 representative fungal OTU isolated from living (i.e., 908 endophyte) and non-living leaves (DLF/LLF). (A) Mean cellulolytic activity as a function of 909 class-level taxonomy and (B) class-level taxonomy and leaf type. (C) Mean growth rate as a 910 function of both class-level taxonomy (S, Sordariomycetes; D, Dothideomycetes) and carbon

911 source (cellulose, lignin, or pectin). Different letters represent significant differences in enzyme 912 activity as a function of fungal class after post-hoc nonparametric multiple comparisons (panel

913 A). Asterisks ${ }^{* *}$ indicate significant differences in cellulolytic activity between fungal OTU

914 found only in non-living leaves vs. fungal OTU isolated from only living leaves $(P<0.05$;

915 Supplemental Table 3). No significant differences were observed between OTU of

916 Sordariomycetes from different leaf types (Supplemental Table 3).

917 


\section{Figure 1}
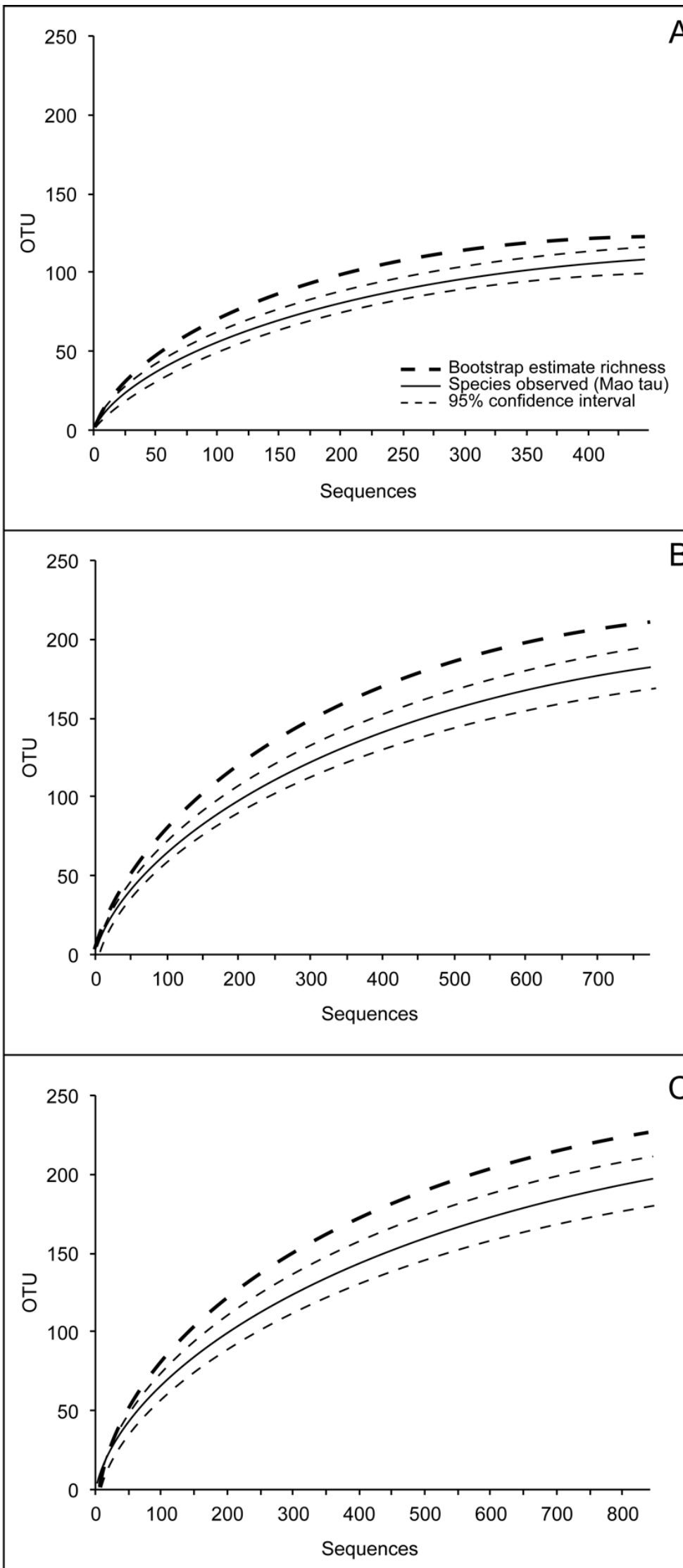
Figure 2

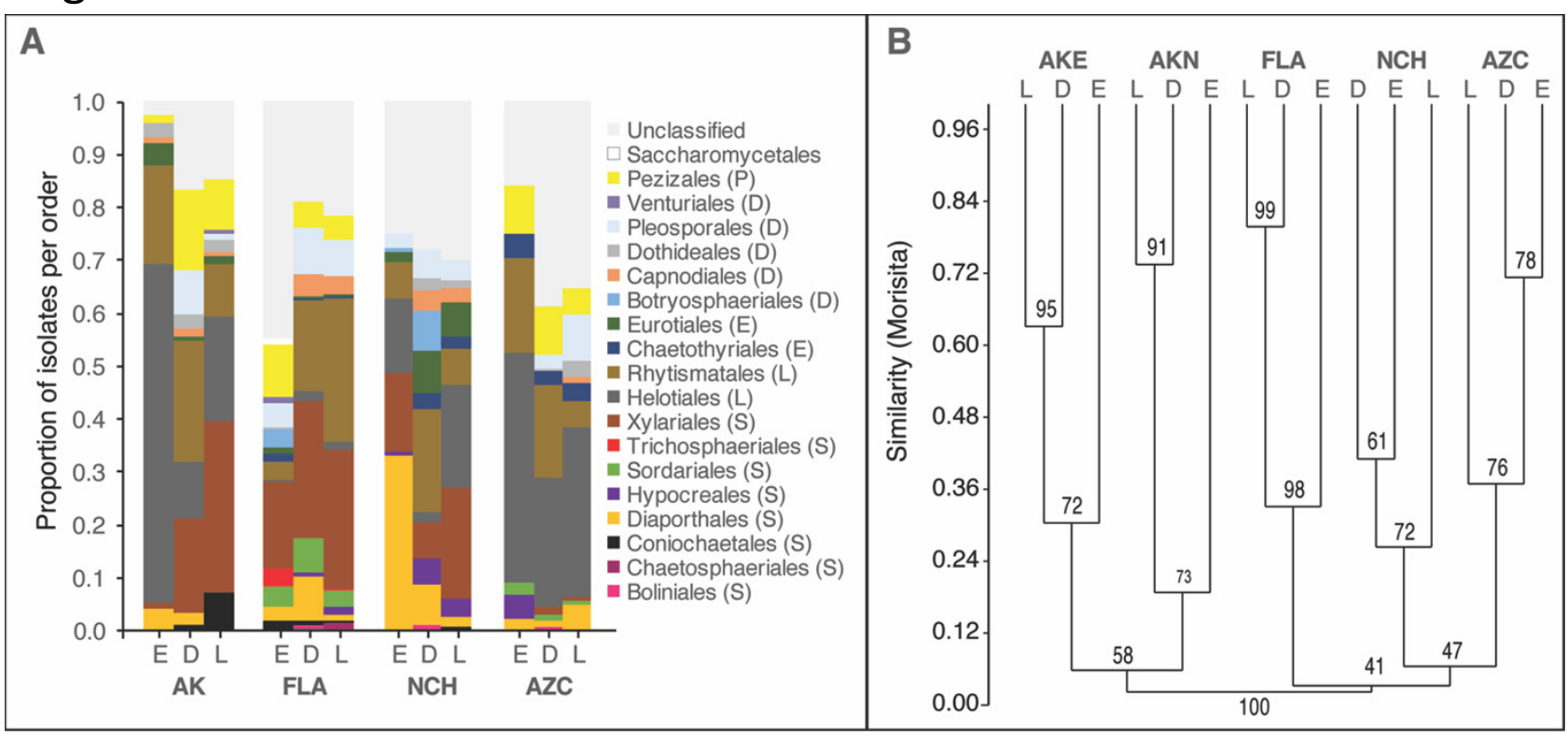




\section{Figure 3}
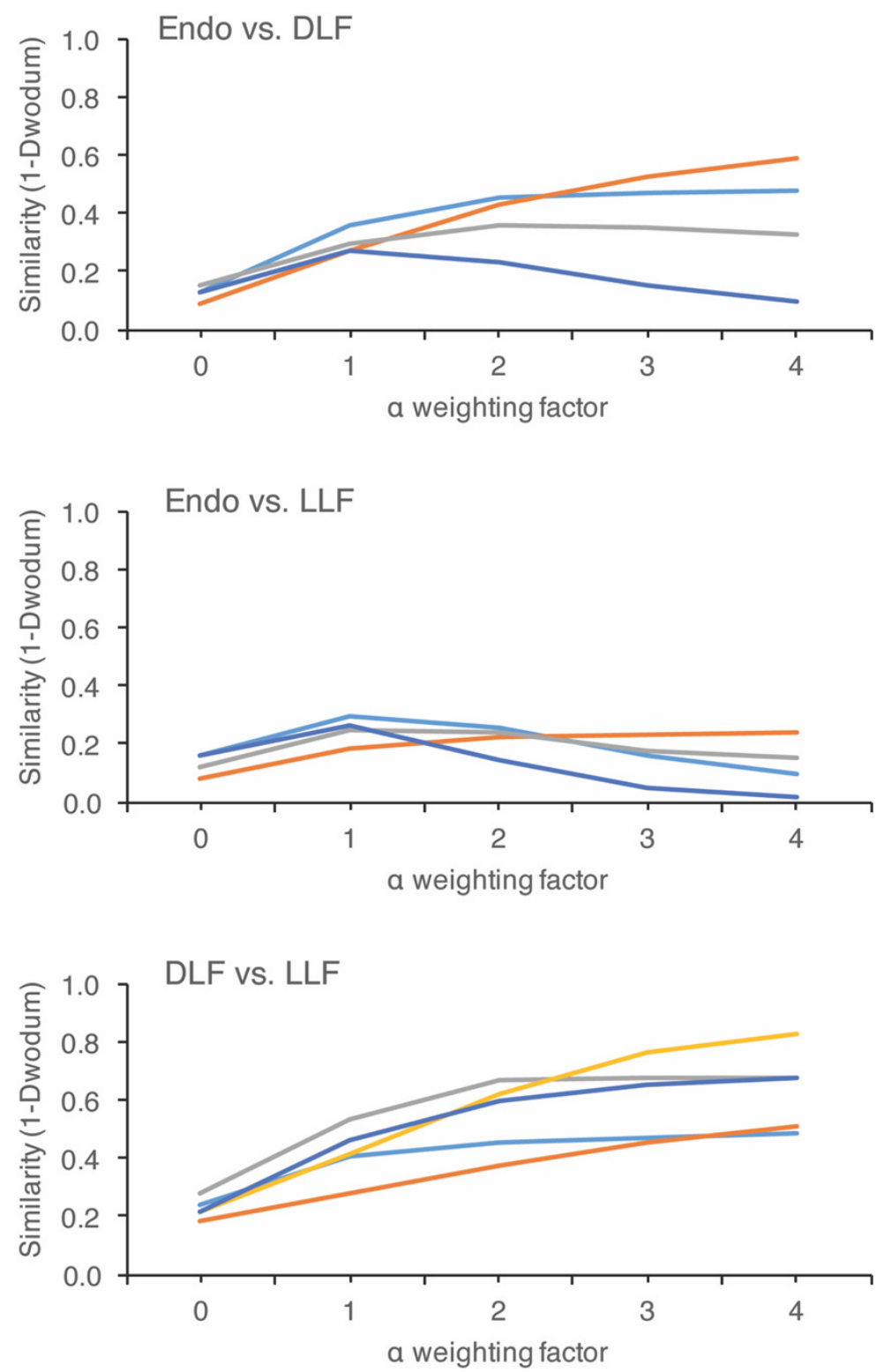

$-\mathrm{AZC}-\mathrm{NCH}-\mathrm{FLA}-\mathrm{AKE}-\mathrm{AKN}$

921

922 
Figure 4

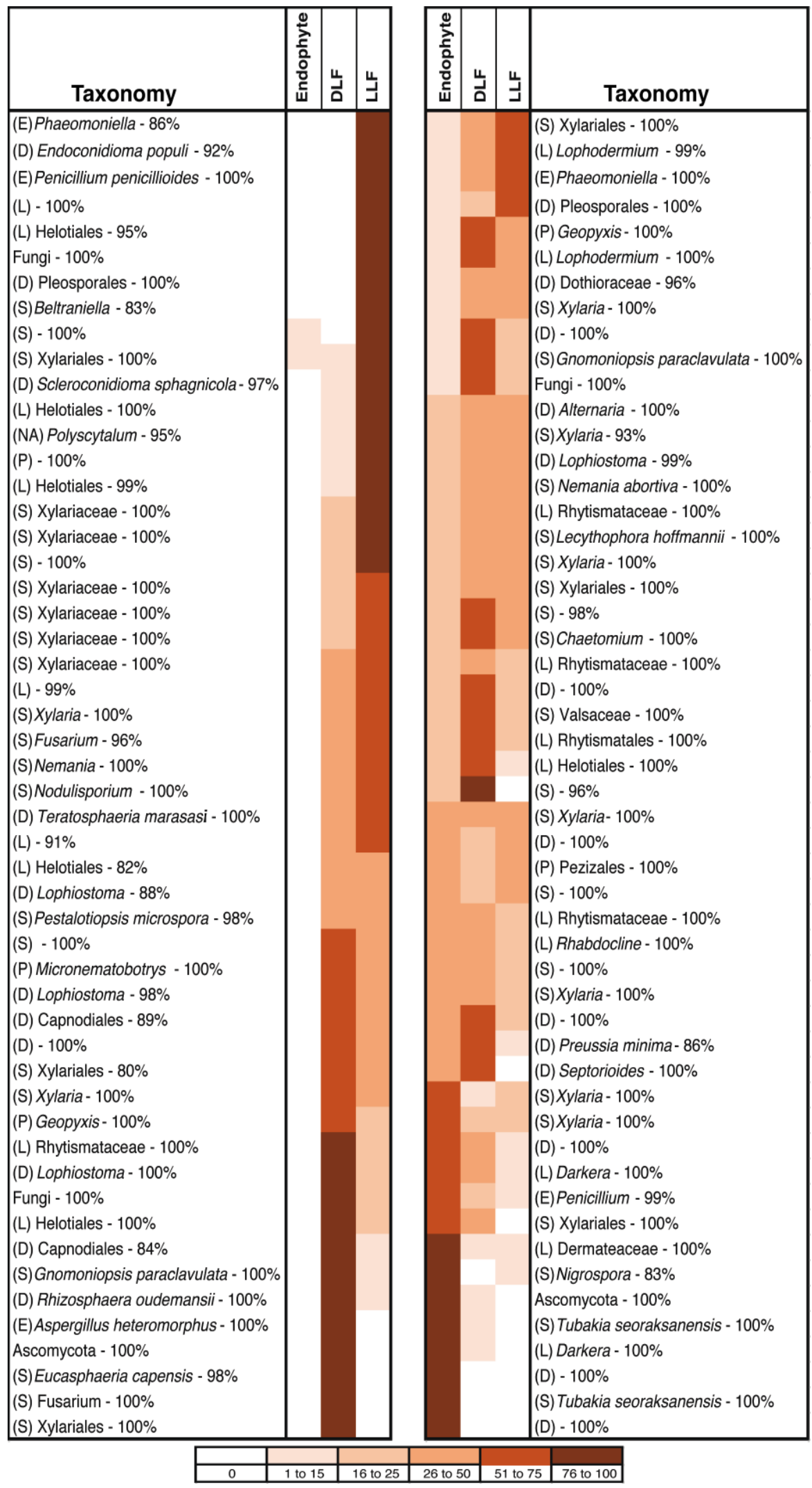


Figure 5

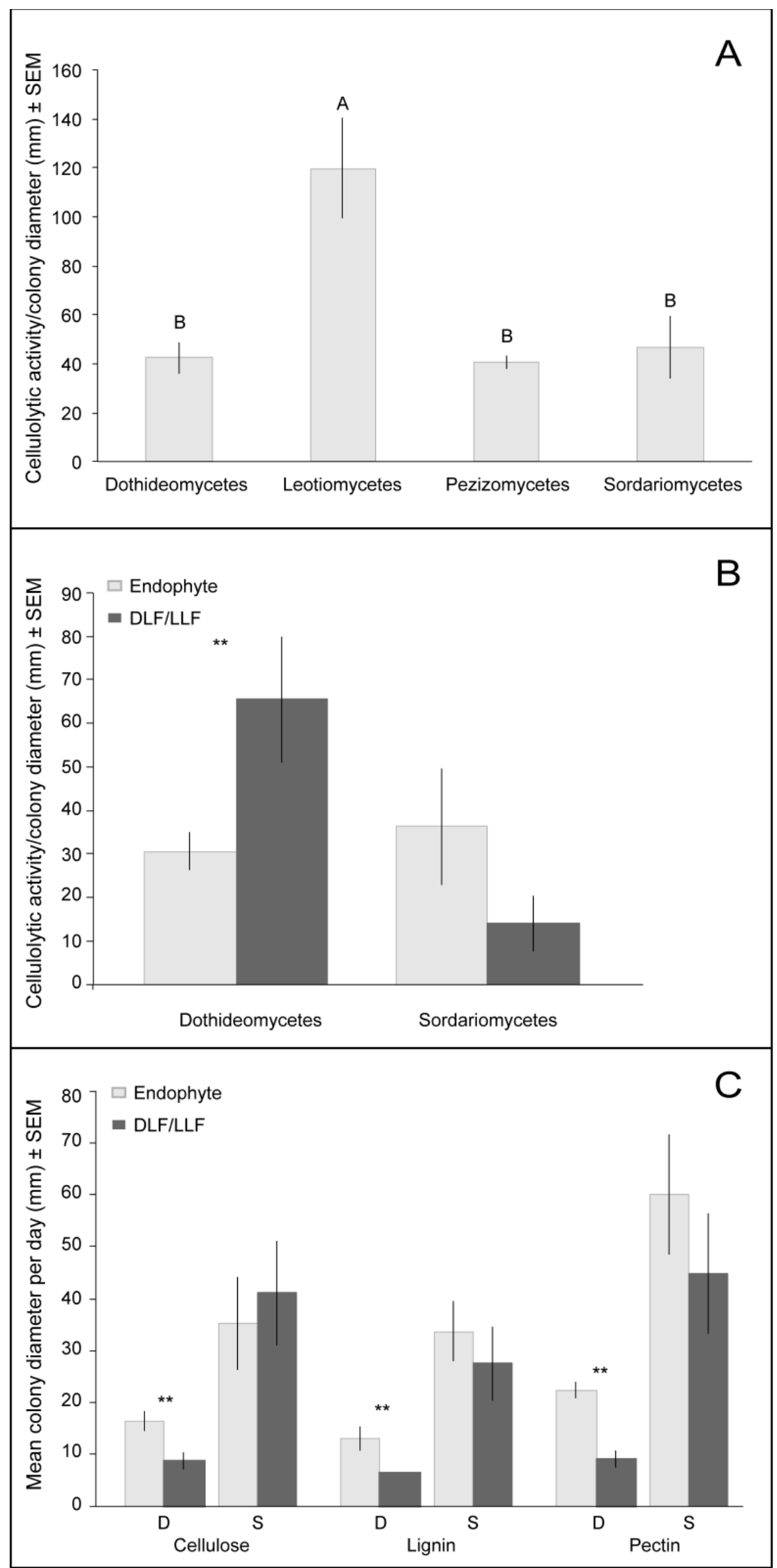

